\title{
A fundamental theory of exchange rates and direct currency trades
}

\author{
Allen Head, ${ }^{a}$ Shouyong Shi $^{*} \cdot b$ \\ ${ }^{a}$ Department of Economics, Queen's University, Kingston, Ontario, Canada, K7L 3N6 \\ *.b Department of Economics, University of Toronto, Toronto, Ontario, Canada, M5S 3G7
}

(This version: December 2002)

\begin{abstract}
In this paper we construct a two-country search model to determine the nominal exchange rate between two fiat monies. Our model allows agents to use any currency to trade for goods in all countries. However, search frictions restrict agents' opportunities for instantaneous arbitrage, and hence make the nominal exchange rate determinate. The nominal exchange rate depends on the two countries' economic fundamentals, including the stocks and growth rates of the two monies. Direct exchanges between currencies are essential and they imply a nominal exchange rate that is different from the relative price between the two currencies in the goods markets. There are persistent violations of the law of one price and purchasing power parity in equilibrium, despite the fact that prices are perfectly flexible and all goods are tradeable between countries. Nominal and real exchange rates can move together in the steady state in response to money growth shocks.
\end{abstract}

Keywords: Exchange Rates; Search; Money; Currency Trade.

JEL classification: F31, C78.

Running Headline: Search and exchange rates

* Corresponding author: Professor Shouyong Shi, Department of Economics, University of Toronto, 150 St. George Street, Toronto, Ontario, Canada, M5S 3G7; (email: shouyong@economics.utoronto.ca); Telephone: 416978-4978; fax: 416-978-6713. This paper is the result of numerous revisions of a previous paper circulated under the title "Search, inflation, and exchange rates" (Head and Shi, 1996). We have received valuable comments from Ruilin Zhou, Neil Wallace, Chris Waller, Alan Stockman, Gregor Smith, Maurice Obstfeld, George Mailath, Beverly Lapham, Narayana Kocherlakota, Gabriele Camera, and the participants of workshops and conferences at Rochester, Queen's, Purdue, Pennsylvania, Kentucky, Indiana, UQAM, Waterloo, York, Northwestern University summer macro workshop (1997), Econometric Society summer meeting (1997), Canadian macro study group meeting (1998), and Texas Monetary Conference (2001). Both authors gratefully acknowledge the financial support from the Social Sciences and Humanities Research Council of Canada. All errors are ours alone. 


\section{Introduction}

In this paper we construct a two-country search model to determine the nominal exchange rate between two fiat monies. Our model allows agents to use any currency to trade for goods in all countries. However, search frictions restrict agents' opportunities for instantaneous arbitrage. These restrictions bind whenever the (gross) growth rates of the two currency stocks exceed the discount factor. In this case the nominal exchange rate is determinate and depends on the two countries' economic fundamentals, including the stocks and growth rates of the two monies. Direct exchanges between currencies are essential and they imply a nominal exchange rate that is different from the relative price between the two currencies in the goods markets. Unless the stocks of the two monies remain constant, there are persistent violations of the law of one price and purchasing power parity in equilibrium despite the fact that prices are perfectly flexible and all goods are tradeable between countries. Nominal and real exchange rates can move together in the steady state in response to money growth shocks.

It is a challenging task to construct theoretical models of the nominal exchange rate. Existing theories have disagreed as to whether the nominal exchange rate is even determinate. Central to the difficulty is to what extent the relative price between two fiat monies is determined by economic fundamentals (e.g., stocks and growth rates of the fiat monies, aggregate output, etc.) or by non-fundamental factors such as expectations. In many monetary models the nominal exchange rate is a function only of the former. Such fundamental theories of exchange rates assume particular roles for each currency. For example, Lucas (1982) assumes a cash-in-advance constraint which requires buyers to use the currency of the seller's country to purchase goods, and Obstfeld and Rogoff (1995) assume that real money balances enter agents' utility functions. In contrast, non-fundamental theories argue that the nominal exchange rate is indeterminate if money is fiat - having no value in either production or utility. For example, using an overlapping generations model, Kareken and Wallace (1981) reach the stark conclusion that a continuum of 
values for the nominal exchange rate are consistent with equilibrium. ${ }^{1}$

The heart of the non-fundamentalist position is that a determinant nominal exchange rate is incompatible with unrestricted substitution between intrinsically useless objects. The cashin-advance assumptions of Lucas (1982) constrain agents to use only one currency in particular trades. In contrast, we allow agents in both countries to use either currency to purchase goods in either country. Unlike Kareken and Wallace (1981) we do not assume that agents can make costless arbitrage between matches in the goods market that involve different currencies, thus generating determinant nominal exchange rates.

In our model there are two countries, between which all goods are tradeable. There are many households in each country. Each household consists of many members and is specialized in production and consumption. Because there is no double coincidence of wants in barter between two randomly matched households, money is necessary for exchanges. Each country issues one currency, which is intrinsically useless. The defining characteristics of a country are that households in each country receive transfers of a particular currency and that they meet each other more frequently than they meet households of the other country. A household can choose how much of each currency to hold and how often to use each currency to transact. There is no restriction on which money must be used in each type of exchange.

There are, however, two restrictions on trade. One is that an individual household member can carry only one money (i.e., not both) into each match, although he/she may carry different monies into matches over time. The second is that agents cannot trade across matches. These restrictions are natural in the search environment. They generate a temporary cash constraint in each money-goods trade, because agents must complete the trade with the money they carry into the match. Such a constraint does not bind when gross money growth rates are equal to the discount factor, in which case the nominal exchange rate is indeterminate. But when gross money growth rates exceed the discount factor, the trading constraint binds and the nominal exchange rate is determined uniquely through direct currency exchange. One currency has a higher price

\footnotetext{
${ }^{1}$ Manuelli and Peck (1990) extended this result to a stochastic environment.
} 
than the other currency if it has a lower initial stock and a lower growth rate in supply. This dependence of nominal exchange rates on fundamentals is similar to that in Lucas (1982), but it does not rely on Lucas's restriction on the particular use of each currency.

There are direct currency-for-currency exchanges between the two countries, provided that the stocks of the two monies do not both remain constant. Households trade currencies across countries in order to achieve optimal portfolios of money holdings, which equate the relative values of the two currencies across countries. Country-specific monetary transfers distort households' money holdings and push the two countries' relative values of the two currencies away from the equilibrium parity. Direct currency trades are an efficient means for households to return their money holdings to the optimal portfolio and to restore equilibrium. These currency trades are redundant in conventional models because they can be replaced by a chain of trades through the goods market, i.e., trading one money for goods first and then goods for the other money. In the search model, however, a direct currency trade is indispensable for balancing portfolios because (1) it takes a shorter time than the chain of trades through the goods market, and (2) it transfers money balances perfectly (linearly) across countries, as opposed to a non-linear transfer through the goods market. ${ }^{2}$ The nominal exchange rate implied by direct currency trades deviates from the relative price between the two currencies implied by the chain of trades in the goods market if and only if the stocks of the two currencies grow at different rates.

If the two monies grow at different rates, then there are also violations of the law of one price in equilibrium. Suppose that money 1 grows more quickly than money 2 and both grow at high rates (the opposite results occur when both monies grow at low rates). Then country 1 buyers pay lower prices than country 2 buyers do, even after controlling for the seller's country index and the currency used. Also, country 1 sellers charge lower prices than country 2 sellers do, even after controlling for the buyer's country index and the currency used. The reason for these violations of the law of one price is that the nominal exchange rate, as the relative price between currencies in direct currency exchanges, can respond to money growth changes in a different magnitude

\footnotetext{
${ }^{2}$ The transfer is non-linear in the goods market because producers' cost, measured in utils, is convex.
} 
from the relative price of goods. At high money growth rates the nominal exchange rate responds to the money growth differential by more than the relative price level of goods across countries, resulting in country 1 households holding less of each money and valuing more of each money than country 2 households. The high valuation of money by country 1 households induces their sellers to charge lower prices and their buyers to pay lower prices than country 2 households.

The violations of the law of one price come from the inability to arbitrage between matches instantaneously, not from traditional sources such as nominal rigidity, the existence of non-traded goods, or "pricing-to-market" by monopolistic sellers (e.g., Betts and Devereux, 2000). The violations of the law of one price also imply deviations from purchasing power parity. Moreover, when both monies grow at high rates, a positive shock to the growth rate of money 1 makes money 1 depreciate against money 2 by more than the increase in the relative price of goods in the two countries, thus leading to a depreciation of country 1's real exchange rate as well.

The economy we study may be seen as extending the search framework of Kiyotaki and Wright $(1989,1993)$, although the specific model we employ is an extension of the one-country model by Shi (1999), who extends search models to allow for both divisible goods and divisible money. ${ }^{3}$ These extensions are necessary for examining money growth, inflation and exchange rate fluctuations, which cannot be examined in models with only divisible goods (e.g., Shi, 1995, and Trejos and Wright, 1995) or only divisible money (e.g., Green and Zhou, 1998).

The theoretical improvements we make enable us to obtain results that have not been found in previous search models of multiple currencies. First, we resurrect the fundamentalists' view that equilibrium nominal exchange rate depends on the growth rates of the two monies. In contrast, the nominal exchange rate is fixed at one by the assumption of indivisible money in Shi (1995) and Trejos and Wright (1996), or by both indivisible money and indivisible goods in Matsuyama et al. (1993), Zhou (1997) and Wang (2000). Second, we uncover an important reason for direct currency trades - positive or negative growth of money supply. In previous search models, only

\footnotetext{
${ }^{3}$ Although the first search model that makes both goods and money divisible is Shi (1997), followed by Shi (1998), the equilibrium concept in the current paper is closer to that in Shi (1999).
} 
Zhou (1997) and Wang (2000) are able to generate (essential) direct trades between currencies. In Zhou (1997) these exchanges are motivated by taste shocks and in Wang (2000) by the risk that government can confiscate private agents' money holdings. Third, the currency market and the goods market imply different relative prices between the two currencies, and this difference is an important source of the violations of the law of one price and purchasing power parity. No such difference exists in previous search models with flexible nominal exchange rates, or, for that matter, in any other model that we know. ${ }^{4}$

Before describing the economy, we want to justify the use of a search model. The search model captures the time-consuming nature of exchanges in the goods market, which is realistic and important for supporting a non-trivial role for fiat money. For simplicity we also model the exchanges in the currency market as random matches. This may not be realistic, because currency exchanges are often centralized and much less costly than goods market exchanges. However, we will argue in section 8 that allowing agents to exchange currencies in a centralized market does not change the qualitative results.

\section{The search economy}

\subsection{Countries, goods, and households}

Time is discrete and lasts forever. There are two countries, two currencies, and $J(\geq 3)$ types of non-storable goods. A country $i(=1,2)$ has the exclusive rights to issue currency $i$ and so currency $i$ is called the domestic currency of country $i$. Both currencies are intrinsically useless; that is, they yield no direct utility and have no use in production. The goods of the same type are identical in the two countries. There are also $J$ types of households in each country. A type $j$ household produces only good $j$ and consumes only good $j+1(\bmod J)$. We call good $j$ household $j$ 's production good and good $j+1$ household $j$ 's consumption good. For simplicity, we assume

\footnotetext{
${ }^{4}$ Recently Craig and Waller (2000) also generate direct currency exchanges in a search model with divisible money and divisible goods. In their model there are some government agents who randomly match with private agents and confiscate the latter's money holdings, as in Li and Wright (1998) and Wang (2000). As in Wang's model, this confiscation risk motivates direct currency exchanges between countries. Craig and Waller's model is not analytically tractable since it yields a non-degenerate distribution of money holdings.
} 
that the utility of consuming $q$ units of consumption goods is a linear function, $u(q)=B q$, where $B>0$ is a constant. The cost of producing $q$ units of production goods, measured in terms of utility, is $\phi(q)=q^{\sigma}$, where $\sigma>1$.

Agents are matched bilaterally according to a random-matching technology described below and their trading histories are private. Because there is no double coincidence of wants in barter, agents must use currency to exchange for consumption goods. However, there is no restriction on which currency should be used in a country. Households can choose to use either currency to transact.

\begin{tabular}{|c|c|c|}
\hline \multicolumn{3}{|c|}{ Members of a household in country $i:$} \\
\hline & measure & holdings \\
\hline money 1: & $n_{i 1}$ & $x_{i 1}=m_{i 1} / n_{i 1}$ \\
\hline money 2: & $n_{i 2}$ & $x_{i 2}=m_{i 2} / n_{i 2}$ \\
\hline producers: & $s$ & N.A. \\
\hline
\end{tabular}

To describe the matching technology, we describe a typical household in a country. Throughout we use lower-case letters to denote the variables of this particular household and capital letters to denote per household variables. A household has a large number of members with total measure one. ${ }^{5}$ Each household member is either a producer or a buyer. Among the buyers, there are holders of money 1 and holders of money 2. In (2.1) we list the notation for the household members of a typical household in country $i$. To simplify the analysis, we assume that the measure of producers in each household is $s_{i}=s, i=1,2$, where $s \in(0,1)$ is a constant. ${ }^{6}$ While this fixes the total measure of buyers in each household, the division of these buyers into holding domestic money and foreign money is endogenous. That is, the household can choose $n_{i k}$, the measure of members of an individual country $i$ household who hold currency $k(i, k=1,2)$. Each money holder holds only one type of money.

\footnotetext{
${ }^{5}$ Throughout this paper we will focus on equilibria where households of different types are symmetric within each country, and will suppress the household subscript $j$ whenever possible. The large number of members in each household makes this focus possible, because it eliminates the possible non-degenerate distribution of money holdings induced by random matching. Otherwise, the analysis is intractable. Alternatively, one may model each agent as the decision unit, who trades a large number of times during each period but consumes only at the end of the period. This alternative approach is more appealing, but it is more difficult to implement because one must take care of the sequential interactions of the agent's activities within a period.

${ }^{6}$ We fix $s$ because in this paper we want to focus on factors associated with households' decisions regarding their portfolio of domestic and foreign currency. It is straightforward to allow households to choose $s$ as well as $n_{i k}$ and doing so will greatly complicate the analysis without affecting the analytical result much. The choice of $s$ in a similar model (but with a single country and currency) is examined in Shi (1999).
} 
Matches are random and bilateral. We use the term "trading match" to refer to a match which may result in trade. There are two types of trading matches. The first is a currency trading match, which occurs between two agents from different countries holding different currencies. The second is a money-goods trading match, which occurs between a currency holder from household $i$ and a producer from household $i+1$. Money-goods trading matches can be further classified according to whether the match is between agents from the same country or from different countries. Let $W_{i k}$ be the aggregate number of money-goods trading matches between holders of money $k$ and producers from the same country $i$. Let $W_{i k}^{f}$ be the aggregate number of trading matches between country $i$ holders of money $k$ and producers from a different country $i^{\prime} \neq i$, where the superscript $f$ indicates matches between countries. We assume the following aggregate matching functions:

$$
W_{i k}=\frac{1}{(1+\alpha) J} N_{i k}^{\psi} s^{1-\psi}, \quad W_{i k}^{f}=\frac{\alpha}{(1+\alpha) J} N_{i k}^{\psi} s^{1-\psi},
$$

where $\alpha, \psi \in(0,1)$. For currency trading matches, we suppress the superscript $f$ and denote $Y_{k k^{\prime}}$ the aggregate number of matches between country 1 holders of money $k$ and country 2 holders of money $k^{\prime} \neq k$, with the following function: ${ }^{7}$

$$
Y_{k k^{\prime}}=\frac{\alpha}{1+\alpha} N_{1 k}^{1 / 2} N_{2 k^{\prime}}^{1 / 2}
$$

The two matching functions emphasize the asymmetry in matching frequencies within and across countries. Given an agent's holdings, the frequency of meeting a foreign agent relative to meeting a domestic agent is $\alpha$, e.g., $W_{i k}^{f}=\alpha W_{i k}$. With $\alpha<1$, an agent meets domestic agents more frequently than meeting foreign agents. In fact, a "country" may be defined as a set of households that (i) have a relatively high probability of meeting each other, and (ii) receive the same currency transfer, described immediately below.

\footnotetext{
${ }^{7}$ Notice that for a money-goods match to be a trading match there must be a single coincidence of wants, which occurs with probability $1 / J$. But for a currency trade, a single coincidence of wants is not necessary, as indicated by the absence of $1 / J$ in $(2.3)$.

The matching functions $W$ and $Y$ can also differ in the weights. In a money-goods trading match, the weights are $\psi$ for money holders and $1-\psi$ for producers. In a money trading match, the weights are $1 / 2$ and $1 / 2$ for each agent. We choose the weights $(1 / 2,1 / 2)$ for money trading matches because money holders are symmetric a priori. We choose the weights $(\psi, 1-\psi)$ in money-goods matches to maintain some generality. All analytical results can hold for $\psi=1 / 2$.
} 
Country $i$ households receive monetary transfers of only money $i$, each receiving $\tau_{i t}$ in lumpsum at the beginning of period $t$. The monetary authority has no other function than administrating these lump-sum transfers (or taxes). Let $M_{k t}$ be the per household stock of money $k$ world-wide at the end of period $t$ and $\gamma_{k t}$ the gross growth rate of money $k$ from period $t$ to period $t+1$. Then,

$$
\tau_{k t+1}=\left(\gamma_{k t}-1\right) M_{k t}, k=1,2 .
$$

\subsection{Trading matches}

In (2.5) we list the terms of trade in money-goods trading matches. In such a match, the buyer makes a take-it-or-leave-it offer, where $x$ is the amount of money paid by the buyer and $q$ is the amount of goods sold by the producer. ${ }^{8}$ In section 3 we will describe in detail how $(x, q)$ are determined. The money-goods trades are distinguished by the producer's country, the buyer's country, and the type of money the buyer holds. Thus, there are eight types of money-goods trades. The first subscript of $x$ indicates the buyer's country and the second subscript indicates the type of money he/she holds. Similarly, the first subscript of $q$ indicates the producer's country and the second subscript indicates the money he/she exchanges for.

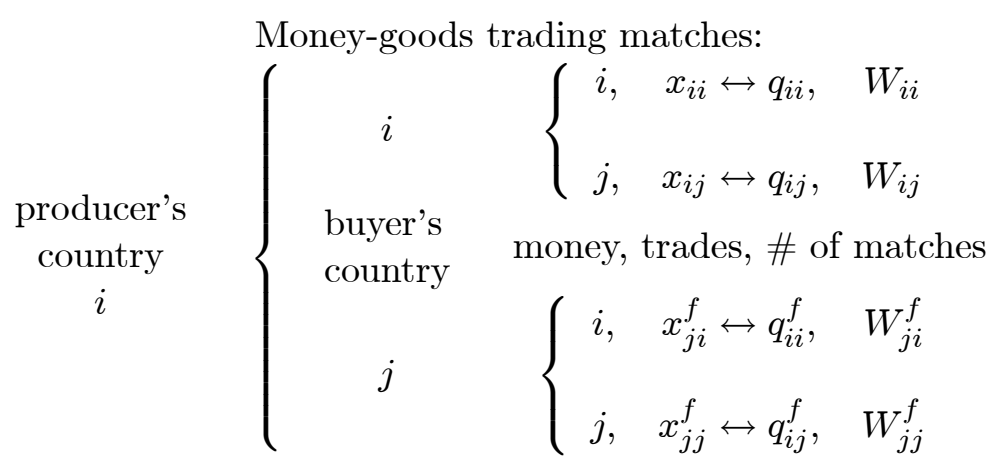

In (2.6) we list currency trades. In a type $I$ currency trade an agent exchanges the domestic currency for the foreign currency, where the exchanged quantity is $f_{11}$ of currency 1 and $f_{22}$ of currency 2 . In a type $I I$ currency trade an agent exchanges the foreign currency for the domestic currency, where the exchange quantity is $f_{21}$ of currency 1 and $f_{12}$ of currency 2 . The two types

\footnotetext{
${ }^{8}$ The analytical results in this paper do not depend much on the take-it-or-leave-it formulation. In an earlier version of this paper we allowed both the buyer and the seller to get a positive fraction of the matching surplus, and the results were similar.
} 
of currency trades may or may not both occur in an equilibrium. In a currency trading match, we assume that the agent from country 1 makes all the offers but he/she must give the country 2 agent at least a half of the total surplus (see section 3 ). ${ }^{9}$

\begin{tabular}{|c|c|c|}
\hline currency exchange & \multicolumn{2}{|c|}{ a country 2 agent holding: } \\
\hline $\begin{array}{c}\text { country } 1 \\
\text { agents holding: }\end{array}$ & money 1 & money 2 \\
\hline money 1 & no trade & $f_{11} \longleftrightarrow f_{22}$ (type I) \\
\hline & & no trade \\
\hline money 2 & $f_{12} \longleftrightarrow f_{21}$ (type II) & $Y_{12}$ \\
\hline \# of matches & $Y_{21}$ & \\
\hline
\end{tabular}

\subsection{Timing of events}

The timing of events in each period $t$ is as follows. At the beginning of the period, each household in country $i$ receives a lump-sum transfer of domestic money, $\tau_{i t}$, but does not receive the transfer of foreign money. After the transfers, the household's money holdings are measured. Denote the household's holding of money $i$ at this time as $m_{i i t}$ and of money $i^{\prime}$ as $m_{i i^{\prime} t}$. Then, the household chooses the measure of members to hold each money, $n_{i k}(k=1,2)$, and divides the stock of each money evenly among the corresponding holders. The household also chooses the terms of trade that the members will propose in trading matches. Matching and trading then follows. (A producer does not produce until a trade agreement is reached with the buyer.) As an important restriction, members cannot borrow from each other during a match, and hence must make a trade under the constraint of the resources they have. After matches and exchanges, members bring back the trade receipts and left-over stocks. Then the household divides the consumption goods evenly among members to consume and time proceeds to the next period.

\footnotetext{
${ }^{9}$ This setup ensures that the two agents each get a half of the total surplus in equilibrium. This eliminates arbitrary fluctuations in the exchange rate caused by asymmetric bargaining. One can also eliminate such arbitrary fluctuations by adopting a sequential bargaining framework where, in each round of bargaining, each side of the match is chosen with probability $1 / 2$ to make the offer. Our setup is much simpler than such sequential bargaining and generates equilibrium outcomes that are very close to the latter. In fact, the two setups generete identical outcomes in the equilibrium where there are two-way currency trades, which is our focus in this paper.
} 


\section{A household's decision problem}

We describe the decision problem in period $t$ of a household in country $i$. Suppress the time index in this section whenever possible and use the symbol ' to indicate one-period future variables.

\subsection{Choices}

A country $i$ household chooses a vector, $h_{i}$, which contains the following elements: (i) the measure of members holding each money $k, n_{i k}$; (ii) future holdings of each money $k, m_{i k}^{\prime}$; and (iii) the trading decisions for the members who will be in trading matches. There are three types of decisions that the household prescribes for the members to carry out in trading matches. The first are the proposals of a buyer (holding money $k$ ) in a trading match with a domestic producer, $\left(x_{i k}, q_{i k}\right)$, and in a trading match with a foreign producer, $\left(x_{i k}^{f}, q_{i^{\prime} k}^{f}\right)\left(i^{\prime} \neq i\right)$. The second are the producer's responses to the offer of a domestic buyer holding money $k, z_{i k} \in\{0,1\}$, and to a foreign buyer holding money $k, z_{i k}^{f} \in\{0,1\}$, where $z=1(0)$ means accepting (rejecting) the offer. The third are the decisions for currency trades. For a country 1 household, the decisions in currency trades are the offers $\left(f_{11}, f_{22}\right)$ (or $\left(f_{12}, f_{21}\right)$ ); for a country 2 household, the decisions are the responses $g_{I}$ or $g_{I I} \in\{0,1\}$ where $g=1(0)$ means accepting (rejecting) the trade.

\subsection{Money-goods trading matches}

Consider first a trading match between a buyer in country $i$ holding money $k$ and a producer in the same country. The terms of trade are $\left(x_{i k}, q_{i k}\right)$. Let $\Omega_{i k}$ be a country $i$ representative household's marginal value of money $k$ one period in the future, discounted to the current period (see a formal definition later). The producer's surplus from the trade is $\left[\Omega_{i k} x_{i k}-\phi\left(q_{i k}\right)\right]$. Under the assumption that the buyer makes a take-it-or-leave-it offer, the buyer's household will prescribe such terms $\left(x_{i k}, q_{i k}\right)$ that exhaust the producer's surplus, i.e.,

$$
\Omega_{i k} x_{i k}=\phi\left(q_{i k}\right), \quad i, k=1,2 .
$$

Moreover, because members are temporarily separated from each other during the match, the household cannot prescribe the terms of trade that require the buyer to propose more money 
than what he/she has. That is,

$$
m_{i k} / n_{i k} \geq x_{i k}, \quad i, k=1,2 .
$$

Now consider a match between the household's producer with a domestic holder of money $k$. The household prescribes the decision $z_{i k} \in\{0,1\}$ for the producer. The buyer in the match from another household proposes $\left(X_{i k}, Q_{i k}\right)$. When this proposal satisfies restrictions like (3.1) and $(3.2), z_{i k}=1 .^{10}$

One can characterize the trade decisions similarly for money-goods matches between agents from different countries. For a trading match between a country $i$ buyer holding money $k$ and a producer from country $i^{\prime} \neq i$, the terms of trade $\left(x_{i k}^{f}, q_{i^{\prime} k}^{f}\right)$ satisfy:

$$
\begin{gathered}
\Omega_{i^{\prime} k} x_{i k}^{f}=\phi\left(q_{i^{\prime} k}^{f}\right), \quad i, k=1,2, \\
m_{i k} / n_{i k} \geq x_{i k}^{f}, \quad i, k=1,2 .
\end{gathered}
$$

When the household's member is a producer in such a trade, the decision is $z_{i k}^{f}=1$ if the partner's proposal $\left(X_{i^{\prime} k}^{f}, Q_{i k}^{f}\right)$ satisfies conditions similar to (3.3) and (3.4).

\subsection{Currency trading matches}

Consider a type $I$ currency trade, i.e., a match between a country 1 holder of money 1 and a country 2 holder of money 2 . The household in country 1 prescribes $\left(f_{11}, f_{22}\right)$ for its member to offer and the household in country 2 instructs its member to either accept the offer or reject the offer. As discussed earlier, we assume that the country 1 household must give at least a surplus, $\max \left\{\Delta_{1} / 2,0\right\}$, to the partner, where $\Delta_{1}$ is the total surplus in a similar trade:

$$
\Delta_{1} \equiv\left(\Omega_{12} F_{22}-\Omega_{11} F_{11}\right)+\left(\Omega_{21} F_{11}-\Omega_{22} F_{22}\right)
$$

The first difference on the right-hand side is the surplus to a country 1 household and the second difference is the surplus to a country 2 household, where $\left(F_{11}, F_{22}\right)$ are the offers in a similar

\footnotetext{
${ }^{10}$ Although the producer gets zero surplus, the decision $z_{i k}=1$ is robust. Mixed strategies are not robust because the buyer can always lower $Q$ slightly to induce the producer to accept the offer with probability 1 .
} 
match and are taken as given by an individual household. In an individual match the restriction on a minimum surplus for the partner can then be written as:

$$
\Omega_{21} f_{11}-\Omega_{22} f_{22} \geq \max \left\{\Delta_{1} / 2,0\right\}
$$

The household from country 2 accepts the trade (i.e., $G_{I}=1$ ) only when the above restriction is satisfied; otherwise $G_{I}=0$.

In addition to the above restriction, the proposer cannot propose to give more than his/her money holding and cannot ask for more than the partner's money holding, due to the temporary separation of agents. Thus, $\left(f_{11}, f_{22}\right)$ must also satisfy:

$$
\begin{aligned}
& m_{11} / n_{11} \geq f_{11}, \\
& M_{22} / N_{22} \geq f_{22} .
\end{aligned}
$$

Now consider a type $I I$ currency trade, i.e., a trade between a country 1 holder of money 2 and a country 2 holder of money 1 . The money holder from country 1 makes all the offers, but the terms of trade $\left(f_{12}, f_{21}\right)$ must satisfy:

$$
\begin{gathered}
\Omega_{22} f_{12}-\Omega_{21} f_{21} \geq \max \left\{\Delta_{2} / 2,0\right\}, \\
m_{12} / n_{12} \geq f_{12}, \\
M_{21} / N_{21} \geq f_{21},
\end{gathered}
$$

where

$$
\Delta_{2} \equiv\left(\Omega_{11} F_{21}-\Omega_{12} F_{12}\right)+\left(\Omega_{22} F_{12}-\Omega_{21} F_{21}\right)
$$

The household from country 2 either accepts the trade $\left(G_{I I}=1\right)$ or rejects the trade $\left(G_{I I}=0\right)$.

\subsection{A household's maximization problem}

We formulate the maximization problem of a country 1 household. The maximization problem of a country 2 household is similar, except that it chooses $\left(g_{I}, g_{I I}\right)$ in currency trades rather than 
the terms of trade. Let the value function of a country 1 household be $v\left(m_{11}, m_{12}\right) .{ }^{11}$ Define the discounted, marginal value of money $k$ as

$$
\omega_{1 k} \equiv \beta v_{k}\left(m_{11}^{\prime}, m_{12}^{\prime}\right), \quad k=1,2,
$$

where $v_{k}$ is the derivative of $v$ with respect to its $k$ th argument. Define $\Omega_{1 k}$ similarly for other households in country 1 and $\Omega_{2 k}$ for households in country 2, which were used earlier.

A country 1 household's expected consumption and production cost in a period are:

$$
\begin{gathered}
\mathfrak{c}=n_{11}\left(\frac{W_{11}}{N_{11}} q_{11}+\frac{W_{11}^{f}}{N_{11}} q_{21}^{f}\right)+n_{12}\left(\frac{W_{12}}{N_{12}} q_{12}+\frac{W_{12}^{f}}{N_{12}} q_{22}^{f}\right), \\
\mathfrak{p}=\left[W_{11} \phi\left(Q_{11}\right)+W_{12} \phi\left(Q_{12}\right)\right]+\left[W_{21}^{f} \phi\left(Q_{11}^{f}\right)+W_{22}^{f} \phi\left(Q_{12}^{f}\right)\right] .
\end{gathered}
$$

In the expression for consumption, the terms in the first bracket are the amount of goods obtained by the household's buyers using money 1 , and the terms in the second bracket are the amount obtained using money 2. In the expression for the production cost, the terms in the first [.] are the cost incurred by the household's producers when meeting domestic buyers and the terms in the second [.] are the cost incurred when meeting foreigner buyers. Notice the distinction between capital letters and lower-case letters.

Taking all other households' choices and aggregate variables (capital-case variables) as given, the household solves the following dynamic programming problem:

$$
(P H 1) \quad v\left(m_{11}, m_{12}\right)=\max _{h_{1}}\left[u(\mathfrak{c})-\mathfrak{p}+\beta v\left(m_{11}^{\prime}, m_{12}^{\prime}\right)\right]
$$

subject to

$$
n_{11}+n_{12}=1-s,
$$

money-goods trading restrictions $(3.1)-(3.4)$,

currency trading restrictions $(3.6)-(3.11)$,

\footnotetext{
${ }^{11}$ We suppress the dependence of this value function on aggregate statistics such as aggregate money holdings $\left(M_{11}, M_{12}, M_{21}, M_{22}\right)$ and money transfers.
} 


$$
\begin{aligned}
m_{11}^{\prime}= & m_{11}-\left[n_{11} \frac{Y_{12}}{N_{11}} G_{I} f_{11}-n_{12} \frac{Y_{21}}{N_{12}} G_{I I} f_{21}\right] \\
& +\left[W_{11} X_{11}+W_{21}^{f} X_{21}^{f}\right]-n_{11}\left[\frac{W_{11}}{N_{11}} x_{11}+\frac{W_{11}^{f}}{N_{11}} x_{11}^{f}\right] \\
& +\left(\gamma_{1}-1\right) M_{1}, \\
m_{12}^{\prime}= & m_{12}+\left[n_{11} \frac{Y_{12}}{N_{11}} G_{I} f_{22}-n_{12} \frac{Y_{21}}{N_{12}} G_{I I} f_{12}\right] \\
& +\left[W_{12} X_{12}+W_{22}^{f} X_{22}^{f}\right]-n_{12}\left[\frac{W_{12}}{N_{12}} x_{12}+\frac{W_{12}^{f}}{N_{12}} x_{12}^{f}\right] .
\end{aligned}
$$

The last two constraints are the laws of motion of the household's money holdings. Let us explain (3.14). (The explanation for (3.15) is similar except that it contains no transfer term, because the household does not receive transfers of money 2.) After the money transfer in the period the household has $m_{11}$ units of money 1 . The household's net payment of money 1 in currencytrading matches is the first [.]. The household's holders of money 1 each trade away $f_{11}$ units of money 1 when meeting foreigners holding money 2 and its holders of money 2 each obtain $f_{21}$ units of money 1 when meeting foreigners holding money 1 . In money-goods trading matches the household's total receipt of money 1 is the second [.] and the total payment of money 1 is the third [.]. That is, the household's producers each obtain $X_{11}$ units of money 1 when trading with domestic buyers and $X_{21}^{f}$ units of money 1 when trading with foreign buyers; the household's holders of money 1 each trade away $x_{11}$ units of money 1 when trading with domestic producers and $x_{11}^{f}$ when trading with foreign producers. After trading in this period the household brings the money balance forward to the next period and, after the money transfer in next period $\left(\gamma_{1}-1\right) M_{1}$, the household's new balance of money 1 is $m_{11}^{\prime}$.

We have set $z_{1 k}$ and $z_{1 k}^{f}$ to 1 for $k=1,2$, anticipating that the offers by other households' buyers will provide a non-negative surplus for the producers in equilibrium. We keep the notation $\left(G_{I}, G_{I I}\right)$ because the total surplus may be negative in some currency matches.

\section{Equilibrium: definition and conditions}

An equilibrium consists of individual households' choices $\left(h_{1}, h_{2}\right)$, representative household's decisions $\left(H_{1}, H_{2}\right)$, and aggregate stocks of each money such that (i) given $\left(H_{1}, H_{2}\right)$ and aggregate money stocks, $h_{1}$ solves $(P H 1)$ and $h_{2}$ solves a similar problem for a country 2 household; (ii) 
$h_{i}=H_{i}$ for $i=1,2$, and (3) money markets clear: $m_{1 k t}+m_{2 k t}=M_{k t}$ for all $t$ and for $k=1,2 .{ }^{12}$

\subsection{Types of equilibria}

There are three possible types of equilibria, distinguished by the directions of the currency trades. The equilibrium is of type $I$ if there are only type $I$ currency trades (i.e., country 1 households exchange money 1 for money 2 with country 2 households), type $I I$ if there are only type $I I$ currency trades (i.e., country 1 households exchange money 2 for money 1 with country 2 households), and type $O$ if there are both types of currency trades. Define

$$
\begin{gathered}
\Pi \equiv \Omega_{12} \Omega_{21}-\Omega_{11} \Omega_{22}, \\
e \equiv\left(\Omega_{11}+\Omega_{21}\right) /\left(\Omega_{12}+\Omega_{22}\right) .
\end{gathered}
$$

The variable $e$ is the world-wide relative value of currency 1 to currency 2, as opposed to countryspecific relative values, $\Omega_{11} / \Omega_{12}$ and $\Omega_{21} / \Omega_{22}$. These country-specific relative values are equal to the world-wide relative values if and only if $\Pi=0$. If $\Pi>0$, country 1 has a lower relative value of currency 1 to currency 2 than country 2 ; if $\Pi<0$, country 1 has a higher relative value of currency 1 to currency 2 than country 2 .

We also define $\left(\mu_{I}, \mu_{I I}\right)$ as:

$$
\mu_{I} \equiv \mu\left(\frac{M_{22}}{N_{22}}-e \frac{M_{11}}{N_{11}}\right), \quad \mu_{I I} \equiv \mu\left(e \frac{M_{21}}{N_{21}}-\frac{M_{12}}{N_{12}}\right)
$$

where the function $\mu(\cdot)$ is such that $\mu(y)=1$ if $y>0$, and $\mu(y)=0$ if $y \leq 0$. In Appendix A we prove the following lemma:

Lemma 4.1. The nominal exchange rate, defined as the relative price of money 1 to money 2 in the currency trade, is equal to $e$ in all three types of equilibria. Each agent in a currency trading match gets a half of the match surplus. Type $I$ equilibrium exists if and only if $\Pi>0$, in which case the currency trade terms are

$$
\left(\begin{array}{l}
F_{11} \\
F_{22}
\end{array}\right)=\left(\begin{array}{c}
1 \\
e
\end{array}\right) \frac{M_{11}}{N_{11}} \mu_{I}+\left(\begin{array}{c}
1 / e \\
1
\end{array}\right) \frac{M_{22}}{N_{22}}\left(1-\mu_{I}\right) .
$$

\footnotetext{
${ }^{12}$ By construction, a household fully takes into account the influence of its choices of money balances on the terms of trade. This is in common with Shi (1999) but in contrast with Shi $(1997,1998)$.
} 
A type II equilibrium exists if and only if $\Pi<0$, in which case the currency trade terms are

$$
\left(\begin{array}{c}
F_{12} \\
F_{21}
\end{array}\right)=\left(\begin{array}{c}
1 \\
1 / e
\end{array}\right) \frac{M_{12}}{N_{12}} \mu_{I I}+\left(\begin{array}{c}
e \\
1
\end{array}\right) \frac{M_{21}}{N_{21}}\left(1-\mu_{I I}\right)
$$

If $\Pi=0$, then $\Delta_{1}=\Delta_{2}=0$, in which case a type $O$ equilibrium exists and any feasible trade quantities of currencies with $F_{22}=e F_{11}$ are consistent with the equilibrium.

Lemma 4.1 states that the two countries exchange currencies directly in both directions only if the relative value between the two currencies is the same across countries. Otherwise, the direct currency trade is one directional, with each country exchanging for the money it values relatively more than the other country.

\subsection{Equilibrium conditions for money-goods trades}

Let $\lambda_{i k}$ be the shadow price (cost) to a household in country $i$ of the money constraint, (3.2). Normalize this shadow price by the number of corresponding trading matches. ${ }^{13}$ Substituting $x_{i k}$ from (3.1) into (3.2) and the household's maximization problem, we can derive the following first-order condition for $q_{i k}$ :

$$
B=\left(\omega_{i k}+\lambda_{i k}\right) \frac{\sigma q_{i k}^{\sigma-1}}{\Omega_{i k}}
$$

The left-hand side is the marginal utility of consumption and the right-hand side is the marginal cost of giving up money $k$ for an additional unit of consumption. To obtain an additional unit of consumption good from a domestic buyer, the buyer must give up $\sigma q_{i k}^{\sigma-1} / \Omega_{i k}$ units of money $k$ (see $(3.1)$ ). The marginal cost of one unit of money $k$ is the sum of expected future value of money $\left(\omega_{i k}\right)$ and the cost generated by a tighter trading restriction $(3.2), \lambda_{i k}$.

Similarly, let $\lambda_{i k}^{f}$ be the shadow price of (3.4), normalized by the number of corresponding trading matches. Then the first-order condition for $q_{i^{\prime} k}^{f}$ is

$$
B=\left(\omega_{i k}+\lambda_{i k}^{f}\right) \frac{\sigma\left(q_{i^{\prime} k}^{f}\right)^{\sigma-1}}{\Omega_{i^{\prime} k}}, \quad i^{\prime} \neq i .
$$

\footnotetext{
${ }^{13}$ For example, when the constraint (3.2) for $i=k=1$ is incorporated into the Lagrangian, it appears as $n_{11} \frac{W_{11}}{N_{11}} \lambda_{11}\left(\frac{m_{11}}{n_{11}}-x_{11}\right)$.
} 


\subsection{Equilibrium conditions for portfolios}

A household's portfolio decision consists of the total holding of each currency and the number of members holding each currency. In equilibrium, the choices of money holdings generate the following equations for the values of monies (see Appendix B for a proof):

$$
\begin{gathered}
\frac{\Omega_{11}}{\beta}=\Omega_{11}^{\prime}+\left(\Lambda_{11}^{\prime} \frac{W_{11}^{\prime}}{N_{11}^{\prime}}+\Lambda_{11}^{f^{\prime}} \frac{W_{11}^{f^{\prime}}}{N_{11}^{\prime}}\right)+\frac{Y_{12}^{\prime} \mu_{I}^{\prime}}{N_{11}^{\prime} \Omega_{22}^{\prime}} G_{I}^{\prime} \Pi^{\prime} \\
\frac{\Omega_{12}}{\beta}=\Omega_{12}^{\prime}+\left(\Lambda_{12}^{\prime} \frac{W_{12}^{\prime}}{N_{12}^{\prime}}+\Lambda_{12}^{f^{\prime}} \frac{W_{12}^{f^{\prime}}}{N_{12}^{\prime}}\right)-\frac{Y_{21}^{\prime} \mu_{I I}^{\prime}}{N_{12}^{\prime} \Omega_{21}^{\prime}} G_{I I}^{\prime} \Pi^{\prime}, \\
\frac{\Omega_{21}}{\beta}=\Omega_{21}^{\prime}+\left(\Lambda_{21}^{\prime} \frac{W_{21}^{\prime}}{N_{21}^{\prime}}+\Lambda_{21}^{f^{\prime}} \frac{W_{21}^{f^{\prime}}}{N_{21}^{\prime}}\right) \\
\frac{\Omega_{22}}{\beta}=\Omega_{22}^{\prime}+\left(\Lambda_{22}^{\prime} \frac{W_{22}^{\prime}}{N_{22}^{\prime}}+\Lambda_{22}^{f^{\prime}} \frac{W_{22}^{f^{\prime}}}{N_{22}^{\prime}}\right),
\end{gathered}
$$

where $\Pi$ is defined in (4.1) and $\left(\mu_{I}, \mu_{I I}\right)$ in (4.3). The left-hand side of each of these equations is the current value of a currency and the right-hand side is the discounted future value of the currency plus the non-pecuniary return to holding the currency in the period. The non-pecuniary return arises from the role of money in alleviating the money constraints in trading matches. For example, to a country 1 household holding money 1, the non-pecuniary return comes from moneygoods trades and direct currency trades, which are captured by the second and third terms on the right-hand side of (4.8). ${ }^{14}$

Optimal decisions on the fractions of members holding each currency, $\left(n_{11}, n_{22}\right)$, obey the following equations in equilibrium (see Appendix B for a proof):

$$
\begin{aligned}
0= & B\left(1-\frac{1}{\sigma}\right)\left(\frac{W_{11}}{N_{11}} Q_{11}+\frac{W_{11}^{f}}{N_{11}} Q_{21}^{f}-\frac{W_{12}}{N_{12}} Q_{12}-\frac{W_{12}^{f}}{N_{12}} Q_{22}^{f}\right) \\
& +\frac{Y_{12}}{N_{11}} G_{I} \Pi\left[\frac{\left(1-\mu_{I}\right) M_{22} / N_{22}}{\Omega_{11}+\Omega_{21}}-\frac{\mu_{I} \Omega_{12} M_{11} / N_{11}}{\Omega_{22}\left(\Omega_{12}+\Omega_{22}\right)}\right] \\
& +\frac{Y_{21}}{N_{12}} G_{I I} \Pi\left[\frac{\left(1-\mu_{I I}\right) M_{21} / N_{21}}{\Omega_{12}+\Omega_{22}}-\frac{\mu_{I I} \Omega_{11} M_{12} / N_{12}}{\Omega_{21}\left(\Omega_{11}+\Omega_{21}\right)}\right],
\end{aligned}
$$

\footnotetext{
${ }^{14}$ The third group of terms do not appear in the equations for $\Omega_{21}$ and $\Omega_{22}$ because a household from country 2 only chooses to accept or reject the currency trades. Since a marginal increase in the money holdings does not change such decisions, its net marginal benefit is zero to a country 2 household in currency trades. Such asymmetry between the two countries disappears in a type $O$ equilibrium (where $\Pi=0$ ).
} 


$$
\begin{aligned}
0= & B\left(1-\frac{1}{\sigma}\right)\left(\frac{W_{22}}{N_{22}} Q_{22}+\frac{W_{22}^{f}}{N_{22}} Q_{12}^{f}-\frac{W_{21}}{N_{21}} Q_{21}-\frac{W_{21}^{f}}{N_{21}} Q_{11}^{f}\right) \\
& +\frac{Y_{12}}{N_{22}} G_{I} \Pi\left[\frac{\mu_{I} M_{11} / N_{11}}{\Omega_{12}+\Omega_{22}}+\frac{\left(1-\mu_{I}\right) M_{22} / N_{22}}{\Omega_{11}+\Omega_{21}}\right] \\
& +\frac{Y_{21}}{N_{21}} G_{I I} \Pi\left[\frac{\mu_{I I} M_{12} / N_{12}}{\Omega_{11}+\Omega_{21}}+\frac{\left(1-\mu_{I I}\right) M_{21} / N_{21}}{\Omega_{12}+\Omega_{22}}\right] .
\end{aligned}
$$

The right-hand side of (4.12) is the net benefit of an increase in $n_{11}$ (accompanied by the same amount of decrease in $n_{12}$ ). The first group of terms summarize the net increase in consumption brought about by the change in the number of money-goods matches to the household's buyers, plus the change in the cost of the trading restrictions in such matches (i.e., costs associated with $\lambda_{1 k}$ and $\lambda_{1 k}^{f}$ ). The second and third groups of terms summarize the change in the surplus from currency trades brought about by the change in $n_{11}$ (and the accompanying change in $n_{12}$ ).

An equilibrium is a solution to the equation system consisting of (3.1)-(3.4), (3.14)-(3.15), (4.1)-(4.13), under symmetry and the money-injection processes in (2.4).

We focus on the type $O$ equilibrium in this paper, because it has the following desirable properties that type $I$ and type $I I$ equilibria do not have: (i) It is immune to our asymmetric treatment of the two countries in currency trades; (ii) it is much simpler than other equilibria and an analytical characterization is possible, because $\Pi=0$ in such an equilibrium; and (iii) its existence does not require extreme money growth rates (see analyses below). In section 8 we will offer some conjectures on type $I$ and type $I I$ equilibria.

In the type $O$ equilibrium the relative value between the two currencies is the same in the two countries (i.e., $\Pi=0$ ) and currencies are exchanged directly in both ways (i.e., $G_{I}=G_{I I}=1$ ). There are two sub-groups of this equilibrium. In one, the trading restrictions bind in money-goods trades (i.e., $\Lambda, \Lambda^{f}>0$ ) and, in the other, these restrictions do not bind. The second sub-group exists only for non-generic parameter values, as we will show below.

\section{Type $O$ equilibrium with binding money constraints}

\subsection{Characterization of equilibrium and the nominal exchange rate}

In this equilibrium, $\Lambda, \Lambda^{f}>0$. Thus, buyers in money-goods trading matches exchange all their money holdings for goods. That is, $X_{i k}=X_{i k}^{f}=M_{i k} / N_{i k}$ for all $i, k=1,2$. For money $i$, let the 
relative holding of an individual domestic holder to an individual foreign holder be

$$
\theta_{i} \equiv \frac{M_{i i} / N_{i i}}{M_{i^{\prime} i} / N_{i^{\prime} i}}, \quad i^{\prime} \neq i, i=1,2
$$

Focus on steady states where $M_{i i} / M_{i}$ and $N_{i k}$ are stationary (so that $\theta_{i}$ is stationary). We have the following Lemma (see Appendix C for a proof):

Lemma 5.1. Consider the steady state of a type $O$ equilibrium and assume $\Lambda_{i k}, \Lambda_{i k}^{f}>0(i, k=$ 1,2). The quantities of goods exchanged in money-goods trades satisfy the following conditions for $i^{\prime} \neq i$ and $i=1,2$ :

$$
\begin{gathered}
\frac{Q_{i i}^{f}}{Q_{i i}}=\theta_{i}^{-1 / \sigma}=\frac{Q_{i^{\prime} i}}{Q_{i^{\prime} i}^{f}} \\
Q_{i i}+\alpha \theta_{i}^{1 / \sigma} Q_{i^{\prime} i}=\frac{\sigma}{B}\left[1+\alpha+\left(\frac{\gamma_{i}}{\beta}-1\right) \frac{N_{i i}}{W_{i i}}\right] Q_{i i}^{\sigma}, \\
Q_{i^{\prime} i}+\alpha \theta_{i}^{-1 / \sigma} Q_{i i}=\frac{\sigma}{B}\left[1+\alpha+\left(\frac{\gamma_{i}}{\beta}-1\right) \frac{N_{i^{\prime} i}}{W_{i^{\prime} i}}\right] Q_{i^{\prime} i}^{\sigma}, \\
Q_{i i^{\prime}}=Q_{i i}\left[A\left(N_{i i}\right)\right]^{1 / \sigma},
\end{gathered}
$$

where

$$
A\left(N_{i i}\right) \equiv \frac{\gamma_{i} / \beta-1+(1+\alpha) W_{i i} / N_{i i}}{\gamma_{i^{\prime}} / \beta-1+(1+\alpha) W_{i i^{\prime}} / N_{i i^{\prime}}}
$$

Eq. (5.2) is the household's ex ante arbitrage conditions for a producer between selling the goods to buyers from different countries - ex ante in the sense that the terms of trade are prescribed before matches occur. The two ratios, $Q_{i i}^{f} / Q_{i i}$ and $Q_{i^{\prime} i} / Q_{i^{\prime} i}^{f}$, both represent the quantity of goods a producer sells to a country $i^{\prime}$ buyer relative to a country $i$ buyer (for the same currency $i$ ), with the only difference being in the producer's country index. Because the two ratios are equal to each other by (5.2), the two countries' producers discriminate the buyers by their origins in the same relative quantity. This quantity discrimination depends solely on the relative individual holding of the currency by the two countries' buyers. A producer sells less goods to a country $i^{\prime}$ buyer than to a country $i$ buyer, for the same currency $i$, if and only if a country $i^{\prime}$ buyer holds a smaller amount of currency $i$ than a country $i$ buyer does (i.e., if $\theta_{i}>1$ ). 
As we will see later, whether $\theta_{i}>1$ depends on the differential between the two monies' growth rates. An equilibrium does not eliminate the quantity discrimination because the same seller cannot be simultaneously in matches with the two types of buyers, ruling out ex post arbitrage between the two matches.

Eq. (5.5) is an ex ante arbitrage condition between the two monies, arising from the household's choice of $n$. It states that the relative quantity of goods that a buyer gets from a domestic producer using the two monies is inversely related to the growth rates of the two monies.

Eqs. (5.3) and (5.4) come from the household's choices of the stocks of the two monies (i.e., from (4.8)-(4.11)). For example, (5.3) states that the "permanent income" from money $i$ (proportional to the term $\left.\left(\gamma_{i} / \beta-1\right) Q_{i i}^{\sigma}\right)$ should be equal to the "cash flow" generated by money $i$ from alleviating the trading restrictions in money-goods trades.

In addition to the restrictions in Lemma 5.1, the $Q$ 's must also satisfy the equilibrium requirement that the relative value of the two currencies be the same in the two countries (i.e., $\Pi=0$ ). This requirement determines a unique distribution of each money in the two countries and hence a unique nominal exchange rate. We establish the following Proposition in Appendix C.

Proposition 5.2. Assume $\Lambda_{i k}, \Lambda_{i k}^{f}>0$. The steady state of a type $O$ equilibrium has the following properties.

(i) The portfolios satisfy $N_{11}=N_{21}, N_{12}=N_{22}, A\left(N_{22}\right)=1 / A\left(N_{11}\right)$, and $\theta_{2}=1 / \theta_{1}$, where $N_{i i}$ is the solution to the following equation (with $N_{i i^{\prime}}=1-s-N_{i i}$ ):

$$
\left(\frac{W_{i i} / N_{i i}}{W_{i i^{\prime}} / N_{i i^{\prime}}}\right)^{\sigma}=A\left(N_{i i}\right)
$$

The solution for $N_{11}$, denoted $N\left(\gamma_{1}, \gamma_{2}\right)$, exists and is unique. Moreover, $N\left(\gamma_{1}, \gamma_{2}\right)$ is a decreasing function of $\gamma_{1}$ and an increasing function of $\gamma_{2}$, with $N(\gamma, \gamma)=N_{12}=(1-s) / 2$.

(ii) The nominal exchange rate is uniquely determined by

$$
\frac{e M_{1}}{M_{2}}=\frac{N\left(\gamma_{1}, \gamma_{2}\right)}{A\left(N\left(\gamma_{1}, \gamma_{2}\right)\right)\left[1-s-N\left(\gamma_{1}, \gamma_{2}\right)\right]}
$$


The nominal exchange rate is a decreasing function of $\gamma_{1}$ and an increasing function of $\gamma_{2}$.

(iii) Let the net payment of money 1 by country 1 households in the two-way currency trades be $D \equiv Y_{12} F_{11}-Y_{21} F_{21}$. Then $M_{11} / M_{1}=M_{12} / M_{2}=\theta_{1} /\left(1+\theta_{1}\right)$ and

$$
\begin{gathered}
\frac{D}{M_{1}}=\frac{\left(\gamma_{1}-1\right)\left(\gamma_{2}-1\right)+\alpha\left[\left(\gamma_{1}-1\right) W_{12} / N_{12}+\left(\gamma_{2}-1\right) W_{11} / N_{11}\right]}{\gamma_{2}-1+2 \alpha W_{12} / N_{12}+\left(e M_{1} / M_{2}\right)\left(\gamma_{1}-1+2 \alpha W_{11} / N_{11}\right)} \\
\theta_{1}=\frac{\gamma_{1}-1+\alpha W_{11} / N_{11}-D / M_{1}}{\alpha W_{11} / N_{11}+D / M_{1}}
\end{gathered}
$$

This proposition states that the portfolio of money holdings, the allocation of members, and the nominal exchange rate are all uniquely determined in the steady state of a type $O$ equilibrium if $\Lambda, \Lambda^{f}>0$. In particular, the nominal exchange rate depends on the fundamentals in intuitive ways. A high domestic money growth, a low foreign money growth, and a high initial stock of domestic money relative to foreign money all make the domestic currency weak. If the two monies have the same growth rate, then the number of household members holding each currency is the same (i.e., $\left.N\left(\gamma_{1}, \gamma_{2}\right)=(1-s) / 2\right)$, in which case $A\left(N\left(\gamma_{1}, \gamma_{2}\right)\right)=1$ and the nominal exchange rate is $e=M_{20} / M_{10}$. If, in addition, the two monies have the same initial stock, the nominal exchange rate is 1 .

For the nominal exchange rate to be determinate, the net amount of currency traded in direct currency-for-currency exchanges must be unique. For each value of net currency trades, $D$, there is a unique portfolio of the two monies in each country and hence a unique relative value between the two monies in each country. The equilibrium value of $D$ is the unique level that ensures the relative value between the two monies to be the same in the two countries. This equilibrium value of $D$ is non-zero in general (see the next subsection for more discussions). In contrast, the gross amounts of currencies traded in either way, $\left(F_{11}, F_{22}\right)$ or $\left(F_{12}, F_{21}\right)$, are indeterminate, which are inconsequential for the equilibrium because the laws of motion of money holdings and hence the money portfolios depend on direct currency trades only through the net amount of currency trades, not through the gross amounts.

Fundamentally, the nominal exchange rate is determinate because each money has its own role in facilitating exchanges beyond its function of a store of value. Since each buyer can hold 
only one kind of money at a time, the temporary separation between agents rules out arbitrage between matches ex post (after matches take place) and, in particular, rules out ex post arbitrage between the two monies. In a money-goods match the temporary separation restricts a buyer from spending more than what he/she has. When such restrictions bind, an additional unit of money has a role in alleviating the trading restrictions. The relative role of the two monies in alleviating such trading restrictions determines the nominal exchange rate. For this reason, the nominal exchange rate responds to the fundamentals.

An informal way to understand the determinacy of the nominal exchange rate is to recall a two-country model with cash-in-advance constraints which require goods to be purchased with the currency issued by the seller's country (e.g., Lucas, 1982). In that model the nominal exchange rate is determinate when the cash-in-advance constraints bind for both currencies. Because the money-goods trading restrictions in our model serve a similar role, it may not be surprising that the nominal exchange rate is determinate in the current equilibrium.

However, it would be misleading to draw a strong similarity between our model and Lucas's. We do not impose Lucas's restriction that buyers must use a particular currency for trades in one country. Rather, agents in our model can use either money to buy goods in each country. This generality allows us to uncover two essential ingredients for a determinate nominal exchange rate. Namely, each buyer can bring only one currency into trade at a time and there cannot be arbitrage between trades during the match. Ex ante (before matches occur), however, agents can choose the quantity of each money to hold and the number of transactions using each money (through the choices of the $n$ 's). These ex ante choices lead to particular dependence of the nominal exchange rate on the fundamentals such as the two monies' growth rates but they do not lead to indeterminate nominal exchange rates.

\subsection{Net currency trades and relative valuation of money across countries}

As we have seen in previous sections, the net amount of direct currency trades and the relative individual money holdings across countries are important for the nominal exchange rate. In this 
subsection we examine how these variables depend on the fundamentals, such as money growth rates. The following lemma summarizes the dependence (see Appendix D for a proof):

Lemma 5.3. Consider the steady state of the type $O$ equilibrium with $\Lambda, \Lambda^{f}>0$. When $\gamma_{2}=1$, $D>0$ if and only if $\gamma_{1}>1$; when $\gamma_{1}=1, D>0$ if and only if $\gamma_{2}>1$. A country 1 household's valuation of money $k$ relative to a country 2 household's is

$$
\frac{\Omega_{1 k}}{\Omega_{2 k}}=\frac{1}{\theta_{1}}\left(\frac{Q_{11}}{Q_{21}}\right)^{\sigma}, \quad k=1,2,
$$

which is less than 1 iff $\theta_{1}>1$. The ratio $\theta_{1}$ has the following properties: (i) $\theta_{1}=1$ if $\gamma_{1}=\gamma_{2}$; (ii) when $\gamma_{1}, \gamma_{2}<1, \theta_{1}>1$ if and only if $\gamma_{1}>\gamma_{2}$; and (iii) when $\gamma_{2}>1$ and $\gamma_{1} \approx \gamma_{2}, \theta_{1}>1$ iff $\left(\gamma_{1}-\gamma_{2}\right)\left(\gamma_{2}-\gamma_{a}\right)<0$ where

$$
\gamma_{a} \equiv 1+(1-\psi)\left[\sigma(1-\beta)+\frac{\beta(\sigma-1)}{J}\left(\frac{2 s}{1-s}\right)^{1-\psi}\right]
$$

Money growth, positive or negative, is the reason for direct currency trades in our model. When both monies have a constant stock, the net currency trade is zero. A sufficient condition for a country to be a net supplier of its currency in the currency trades is that the supplies of both monies expand, and a sufficient condition for a country to be a net recipient of its currency is that the supplies of both monies shrink. To explain these results, suppose that the supplies of both monies expand. Both monies deteriorate in value but, since only the country's own residents receive the country's monetary transfers, the value of money 1 relative to money 2 deteriorates more quickly in country 1 than in country 2. Thus it is mutually desirable for the two countries' households to exchange their own currency for the foreign currency in the currency trades. The net amount of currency traded is such that equalizes the relative value of the two monies between the two countries. The net currency trade is reversed if the monetary transfers are negative.

Lemma 5.3 also states that the two countries' valuations of a given currency are the same if and only if the two monies' growth rates are the same. When the two monies have different growth rates, one country values both monies more than the other country. Exactly which country values both monies more depends on the equilibrium distribution of monies. When $\theta_{1}>1$ (and 
so $\theta_{2}<1$ ), country 1 holds more than a half of each money and so values each money less than country 2. If $\theta_{1}<1$, country 1 holds less than a half of each money and so values each money more than country 2. (In both cases, the relative value between the two monies is the same in the two countries.)

The variable $\theta_{1}$ depends on the differential between the two monies' growth rates. To see this, set $\gamma_{2}$ at an arbitrary level $\gamma$, where $\gamma>\beta$. If $\gamma_{1}=\gamma$ the two countries are perfectly symmetric and each country holds a half of the stock of each money, resulting in $\theta_{1}=1$. If $\gamma_{1}>\gamma$, the two countries exchange their domestic money for foreigner money in direct currency exchanges in order to equate their relative values between the two monies. If money growth rates are not very high (i.e., $\gamma_{1}, \gamma_{2}<\gamma_{a}$ ), the relative value of the two monies is sensitive to changes in the nominal exchange rate and so a moderate depreciation of money 1 can restore the equilibrium. In this case, direct currency trades pass less than a half of money 1 injection from country 1 into country 2 , leaving country 1 holding more of money 1 than country 2 (i.e., $\theta_{1}>1$ ). Since money 1 grows at a higher rate than money 2 and a large fraction of the newly created money 1 is used to exchange for money 2, country 1 also holds more of money 2 than country 2 in the steady state (i.e., $\left.\theta_{2}<1\right) .{ }^{15}$

If money growth rates are very high (i.e., $\gamma_{1}, \gamma_{2}>\gamma_{a}$ ), however, the relative value of the two monies is not sensitive to changes in the nominal exchange rate. When money 1's growth rate is higher than money 2's, money 1 must depreciate sufficiently to restore the equality between the two countries' relative values of the two monies. The large depreciation entails country 1 households to increase significantly the amount of money 1 exchanged for a given quantity of money 2 in the currency trades. In this case, the currency trades over-correct the asymmetric money injection and result in country 2 holding more of both monies than country $1 .^{16}$

\footnotetext{
${ }^{15}$ To see this, consider the example $\gamma_{2}=1$ and $\gamma_{1}>1$. In this case, $\theta_{1}>1$, as explained above. Because country 1 households obtain money 2 from the currency trades while country 2 households do not receive transfers of money 2 , country 1 also holds more of money 2 than country 2 .

${ }^{16}$ The critical level of the money growth rate that distinguishes the above two cases, $\gamma_{a}$, can be arbitrarily close to 1 when $\psi \rightarrow 1$ and arbitrarily large when $s \rightarrow 1$.
} 


\subsection{Existence and uniqueness of equilibrium}

So far we have presumed that the money constraints bind in money-goods trading matches. To establish the existence of a type $O$ equilibrium with $\Lambda, \Lambda^{f}>0$, we must show that $\Lambda, \Lambda^{f}>0$ indeed. The following proposition accomplishes this task for restricted parameter values.

Proposition 5.4. Assume that $\gamma_{1}$ and $\gamma_{2}$ are sufficiently close to each other. Then a type $O$ equilibrium with $\Lambda, \Lambda^{f}>0$ exists and is unique if and only if $\gamma_{1}, \gamma_{2}>\beta$ and $\gamma_{1}, \gamma_{2} \in[1 /(1+$ $\alpha), 1+\alpha /(1+\alpha)]$

Proof. We supply the proof for $\gamma_{1}=\gamma_{2}$. By continuity, the proposition holds for $\gamma_{1}$ and $\gamma_{2}$ sufficiently close to each other. Set $\gamma_{1}=\gamma_{2}=\gamma$. Proposition 5.2 implies $A(N)=1$ and $N_{i k}=$ $(1-s) / 2$ for all $i, k=1,2$; Lemma 5.3 implies $\theta_{1}=1$. Then (5.2)-(5.5) imply $Q_{i k}^{f}=Q_{i k} \equiv Q$ for all $i, k=1,2$. In this case, (C.2) and (C.3) in Appendix C show that the requirements $\Lambda_{i k}>0$ and $\Lambda_{i k}^{f}>0$ for all $i, k=1,2$ are equivalent to one condition, $Q^{\sigma-1}<B / \sigma$. This condition is equivalent to $\gamma>\beta$ once we solve the $Q$ 's from (5.3). Finally, since $0 \leq F_{11} \leq M_{11} / N_{11}$ and $0 \leq F_{21} \leq M_{21} / N_{21}$, the equilibrium must satisfy $-Y_{21} M_{21} / N_{21} \leq D \leq Y_{12} M_{11} / N_{11}$. Using (5.9) to solve for $D / M_{1}=(\gamma-1) / 2$, we can rewrite these requirements as $1 /(1+\alpha) \leq \gamma \leq 1+\alpha /(1+\alpha)$. Clearly, there is only one such equilibrium.

The requirement that the two monies have similar growth rates is sufficient but may not be necessary for existence. ${ }^{17}$ Another requirement for existence is that the money growth rates are bounded below and above. If both monies grow at rates higher than $1+\alpha /(1+\alpha)$ or lower than $1 /(1+\alpha)$, at least one side of the currency trade must trade more than what he/she has in order to equalize the relative value of the two monies between the two countries, which is clearly not feasible. In these cases, either the equilibrium with $\Pi>0$ exists (if $\gamma_{1}, \gamma_{2}>1+\alpha /(1+\alpha)$ ) or the equilibrium with $\Pi<0$ exists (if $\gamma_{1}, \gamma_{2}<1 /(1+\alpha)$ ).

\footnotetext{
${ }^{17}$ To show existence for general $\left(\gamma_{1}, \gamma_{2}\right)$ one must verify separately that every one of the eight $\Lambda$ 's is positive and this is a daunting task.
} 
For the equilibrium to exist, the (gross) money growth rates must also be greater than the discount factor, i.e., the money growth rates must exceed the Friedman rule. If both money growth rates are equal to $\beta$, the two monies yield rates of return equal to the discount rate and the money-goods trading restrictions do not bind, as shown in the next section.

\section{Type $O$ equilibria with non-binding money constraints: indeterminacy}

We briefly examine equilibria in which the trading restrictions in money-goods trades do not bind and show that the nominal exchange rate is indeterminate in such cases.

When $\Lambda_{i k}=\Lambda_{i k}^{f}=0$ for all $i, k=1,2, \Omega_{i k}=\beta \Omega_{i k}^{\prime}$ for all $i, k=1,2$ (see (4.8)-(4.11)). That is, all monies have the same rate of return, $1 / \beta$, regardless of which money it is or who holds it. The same conditions imply that the nominal exchange rate must be constant over time. That is,

$$
e=\frac{\Omega_{i 1}}{\Omega_{i 2}}=\frac{\Omega_{i 1}^{\prime}}{\Omega_{i 2}^{\prime}}=e^{\prime}
$$

However, for a money to have a rate of return $1 / \beta$, its supply must shrink at a rate equal to the discount rate, as stated below (see Appendix E for a proof):

Proposition 6.1. For there to be a steady state of a type $O$ equilibrium with $\Lambda_{i k}, \Lambda_{i k}^{f}=0$ for all $i, k=1,2$, the money growth rates must be $\gamma_{1}=\gamma_{2}=\beta$. If $\gamma_{1}=\gamma_{2}=\beta$ and each country holds both monies, then all money holdings shrink at the discount rate, i.e., $M_{i k}^{\prime} / M_{i k}=\beta$ for all $i, k=1,2$. There is a continuum of equilibrium values of the nominal exchange rate.

Since money holdings all shrink geometrically at rate $\beta$, each money gives its holder a rate of return equal to the discount rate, regardless of the initial distribution of the money between the two countries. The nominal exchange rate, however, depends on the initial money distribution across countries, and so the indeterminacy of the initial money distribution results in indeterminate nominal exchange rates. This indeterminacy is a reminiscent of the result in Kareken and Wallace (1981). However, indeterminacy is non-generic in our model, because it occurs only when $\gamma_{1}=\gamma_{2}=\beta$ 


\section{Relative prices and real exchange rates}

We return to the type $O$ equilibrium with $\Lambda, \Lambda^{f}>0$ and investigate relative prices. The proofs for this section are straightforward and are omitted. ${ }^{18}$

\subsection{Violations of the law of one price}

There are violations of the law of one price in equilibrium. To illustrate, we define the following nominal prices for $i, k=1,2$ and $i^{\prime} \neq i$ :

$$
p_{i k} \equiv \frac{M_{i k} / N_{i k}}{Q_{i k}}, \quad p_{i k}^{f} \equiv \frac{M_{i^{\prime} k} / N_{i^{\prime} k}}{Q_{i k}^{f}} .
$$

The superscripts and the subscripts of the $p$ 's have the same interpretations as those of the $Q$ 's.

For example, $p_{i k}^{f}$ is the price level in money $k$ in a trade between a country $i$ producer and a buyer from country $i^{\prime} \neq i$ holding money $k$.

Corollary 7.1. Controlling for the seller's country index and the currency used, a country 1 buyer pays the following prices relative to a country 2 buyer:

$$
\frac{p_{11}}{p_{11}^{f}}=\frac{p_{21}^{f}}{p_{21}}=\frac{p_{22}^{f}}{p_{22}}=\frac{p_{12}}{p_{12}^{f}}=\theta_{1}^{1-\frac{1}{\sigma}} .
$$

Controlling for the buyer's country index and the currency used, a country 1 seller charges the following prices relative to a country 2 seller:

$$
\frac{p_{11}}{p_{21}^{f}}=\frac{p_{12}}{p_{22}^{f}}=\frac{p_{11}^{f}}{p_{21}}=\frac{p_{12}^{f}}{p_{22}}=\left(\frac{\Omega_{1 k}}{\Omega_{2 k}}\right)^{-1 / \sigma}=\frac{Q_{21}}{Q_{11}} \theta_{1}^{1 / \sigma} .
$$

These relative prices are greater than 1 if and only if $\theta_{1}>1$. Thus, they are equal to 1 when $\gamma_{1}=$ $\gamma_{2}$, and greater than one either when $\gamma_{2}<\gamma_{1}<1$ or when $\gamma_{1} \approx \gamma_{2}>1$ and $\left(\gamma_{1}-\gamma_{2}\right)\left(\gamma_{2}-\gamma_{a}\right)<0$.

The law of one price holds when $\gamma_{1}=\gamma_{2}$; otherwise it is violated. When money growth rates are not too high (i.e., if $\gamma_{1}, \gamma_{2}<\gamma_{a}$ ), the violation of the law of one price is as follows. There is price discrimination against buyers from the country whose money grows more quickly than the

\footnotetext{
${ }^{18}$ For the proofs, express all variables as functions of $\left(\theta_{1}, Q_{11}, Q_{21}\right)$ using (5.2)-(5.5) and Proposition 5.2. Then apply Lemma 5.3.
} 
other country's, no matter where the buyers make the purchases and no matter which currency they use. The sellers in the country whose money grows more quickly charge higher prices, no matter where the buyers come from and no matter which currency they use. The opposite is true when money growth rates are very high (i.e., when $\gamma_{1}, \gamma_{2}>\gamma_{a}$ ).

These are strong violations of the law of one price, because the transactions that we use to define the above relative prices involve the same currency and the same country index for the seller/buyer. Such violations occur because country 1 households value both monies less than country 2 households if and only if $\theta_{1}>1$ (see Lemma 5.3). Thus, when $\theta_{1}>1$, country 1 households are willing to pay higher prices than country 2 households for any given currency and any given country's sellers; they also demand more money than country 2 households from selling goods to any given country's buyers with any given currency.

\subsection{Real exchange rates}

The violations of the law of one price generate deviations from the purchasing power parity, i.e., the real exchange rate is not one. The standard notion of the real exchange rate is the relative price of goods sold by country 1 sellers to goods sold by country 2 sellers, after converting the prices into the same currency. ${ }^{19}$ There are a variety of relative prices between the two countries' goods in the current model, depending on the extent to which we want to restrict the types of transactions involved. The relative prices in (7.3) are narrow measures of the real exchange rate, which fix the buyers' country index and the type of currency used. According to these measures, country 1 goods are more expensive than country 2 goods if and only if $\theta_{1}>1$.

One can still fix the type of currency used but aggregate over all transactions taken place in a country with that currency. This yields a broader measure of the real exchange rate than those in (7.3). We define the average price of goods sold in country $i$ for money $k$ (to both countries'

\footnotetext{
${ }^{19}$ One can also define the real exchange rate as the relative price of goods purchased by country 1 households to goods purchased by country 2 goods, but this leads to the same analytical features of the real exchange rate.
} 
buyers), weighted by the transaction quantity, as

$$
P_{i k} \equiv \frac{W_{i k} Q_{i k} p_{i k}+W_{i^{\prime} k}^{f} Q_{i k}^{f} p_{i k}^{f}}{W_{i k} Q_{i k}+W_{i^{\prime} k}^{f} Q_{i k}^{f}}, \quad i^{\prime} \neq i ; i, k=1,2 .
$$

The real exchange rate implied by these prices is

$$
R_{k} \equiv P_{1 k} / P_{2 k}
$$

Note that we do not need to multiply this price ratio by the nominal exchange, because $P_{1 k}$ and $P_{2 k}$ are already measured in the same currency $(k)$. Also note that an increase in $R_{k}$ is an appreciation of the goods in country 1 relative to goods in country 2 .

One can define an even broader measure of the relative price by aggregating over all goods sold in a country. The average price of all goods sold in country $i$ is

$$
P_{i} \equiv \frac{e\left(W_{i 1} Q_{i 1} p_{i 1}+W_{i^{\prime} 1}^{f} Q_{i 1}^{f} p_{i 1}^{f}\right)+\left(W_{i 2} Q_{i 2} p_{i 2}+W_{i^{\prime} 2}^{f} Q_{i 2}^{f} p_{i 2}^{f}\right)}{W_{i 1} Q_{i 1}+W_{i^{\prime} 1}^{f} Q_{i 1}^{f}+W_{i 2} Q_{i 2}+W_{i^{\prime} 2}^{f} Q_{i 2}^{f}} .
$$

Note that $P_{1}$ and $P_{2}$ are both measured in terms of money 2. The real exchange rate corresponding to these prices is

$$
R \equiv P_{1} / P_{2}
$$

Corollary 7.2. In a type $O$ equilibrium with $\Lambda, \Lambda^{f}>0$,

$$
R=R_{1}=R_{2}=\left(\frac{Q_{21}}{Q_{11}} \theta_{1}^{1 / \sigma}\right) \frac{\left(\alpha+\theta_{1}\right)\left(1+\alpha \theta_{1}^{1 / \sigma}\right)}{\left(1+\alpha \theta_{1}\right)\left(\alpha+\theta_{1}^{1 / \sigma}\right)} .
$$

Moreover, $R>1$ if and only if $\theta_{1}>1$.

The different measures of the real exchange rate all have the same value in equilibrium. The purchasing power parity is violated, unless the two monies have the same growth rate (in which case $\theta_{1}=1$ ). Country 1 goods are more expensive than country 2 goods if and only if country 1 holds a larger fraction of money 1 (and money 2) than country 2. With Lemma 5.3, this implies that the real exchange rate is greater than one if (i) $\gamma_{2}<\gamma_{1}<1$, or (ii) $\gamma_{a}>\gamma_{1}>\gamma_{2}>1$ and $\gamma_{1} \approx \gamma_{2}$. These deviations from the purchasing power parity directly reflect the price differentials 
in Corollary 7.1. For example, if money 1 grows more quickly than money 2 (but $\gamma_{1}, \gamma_{2}<\gamma_{a}$ ), then country 1 households hold more of each currency, their sellers charge higher prices, and so goods in country 1 are more expensive than goods in country 2.

Another interesting feature is that the real exchange rate and the nominal exchange rate may or may not move in the same direction in the steady state when responding to monetary shocks. Starting from a common growth rate $\gamma$ for the two monies, we consider a marginal increase in the growth rate of money 1 and unchanged growth of money 2. In this case, money 1 depreciates against money 2 and so the nominal exchange rate $e$ falls (see Proposition 5.2). In contrast, the real exchange rate rises if $\gamma<\gamma_{a}$ and falls if $\gamma>\gamma_{a}$. The explanation is as follows. When $\gamma<\gamma_{a}$, only a moderate depreciation in the nominal exchange rate is necessary for eliminating the potential cross-country inequality between the relative values of the two monies caused by the shock (see the explanation for Lemma 5.3). This depreciation is not enough to balance the increase in nominal prices in country 1 goods (in terms of money 1) relative to country 2 goods (in terms of money 2), and so the real exchange rate rises. When $\gamma>\gamma_{a}$, a large depreciation of the nominal exchange rate is necessary for restoring equilibrium, which dominates the increase in nominal prices of goods and leads to a depreciation in the real exchange rate.

It is remarkable that our model generates violations of the law of one price and possible comovements between nominal and real exchange rates. Our model does not have the traditional culprits of such anomalies, such as nominal rigidity, the existence of non-traded goods, "pricingto-market" by monopolistic sellers (e.g., Betts and Devereux, 2000), or the restriction on the use of each currency to a particular country. What generates the results here is search frictions. By limiting agents' ability of making arbitrage between matches, these frictions generate price differentials in even narrowly defined categories of transactions, and hence the results discussed above. 


\subsection{The wedge between the currency market and the goods market}

With search frictions, the relative price between the two currencies implied by direct currency trades (i.e., the nominal exchange rate $e$ ) is different from the relative price implied by moneygoods trades. In money-goods trades, there are four narrowly defined relative prices between the two monies:

$$
\rho_{i} \equiv p_{i 2} / p_{i 1}, \quad \rho_{i}^{f} \equiv p_{i 2}^{f} / p_{i 1}^{f}, \quad i=1,2
$$

These definitions have controlled for the sellers' country index (the subscript $i$ ) and the buyers' country index (the superscript). $\rho_{1}$ is the relative price between the two monies implied by trades between country 1 sellers and country 1 buyers using the two monies, and $\rho_{1}^{f}$ is the relative price between the two monies implied by trades between country 1 sellers and country 2 buyers using the two monies. ${ }^{20}$ It can be verified that $\rho_{i}=\rho_{i}^{f}=e / r$ for $i=1,2$, where

$$
r \equiv\left[A\left(N_{11}\right)\right]^{\frac{1}{\sigma}-1}
$$

From the features of $N_{11}$ in Proposition 5.2, we know that $r<1$ if and only if $\gamma_{1}>\gamma_{2}$. That is, the relative price of money 1 to money 2 in the goods market exceeds that in the currency market if and only if money 1 grows more quickly relative to money 2 . Moreover, $r$ decreases in $\gamma_{1}$ and increases in $\gamma_{2}$, which implies $e^{-1}\left|d e / d \gamma_{k}\right|>\rho^{-1}\left|d \rho / d \gamma_{k}\right|$ for $k=1,2$. That is, the nominal exchange rate responds to money growth shocks more than does the relative price between the two currencies implied by the goods market. This discrepancy between the two markets arises for two reasons. First, direct currency exchanges are a less time-consuming way to trade monies than goods-market exchanges. Second, direct currency exchanges transfer money balances between countries perfectly (linearly), while goods market exchanges transfer money balances imperfectly (non-linearly) due to the convex production cost function.

Previous models of multiple currencies do not generate this discrepancy between the relative prices in the two markets. In Walrasian models, where agents can make instantaneous arbitrage

\footnotetext{
${ }^{20}$ Since each of these relative prices involves prices of goods sold in the same country, it is qualitatively different from the relative prices between different countries used in the definitions of the real exchange rate.
} 
between the goods market and the money market, the equilibrium has $e=\rho$. In cash-in-advance models such as Lucas (1982), it is not possible to define relative prices like $\rho$, because the cashin-advance assumption prohibits households in a country from selling goods for both monies. If one relaxes the assumption to allow all sellers to sell goods for both monies, then again $e=\rho=1$ as a result of arbitrage. In previous search models, either $\rho$ is exogenously fixed at 1 as a result of indivisible money (e.g., Matsuyama et al., 1993, Zhou, 1997, and Wang, 2000), or there are no direct currency-for-currency trades that explicitly define the nominal exchange rate (e.g., Shi, 1995, and Trejos and Wright, 1996).

\section{Conclusion}

In this paper we construct a two-country, search monetary model to determine the nominal exchange rate between two fiat monies. Our model uncovers two essential ingredients for a determinate nominal exchange rate, i.e., an agent cannot make instantaneous arbitrage between trades in the goods market and an agent cannot bring different monies into the same trade. Unlike cash-in-advance models, our model imposes no restriction on which money must be used in a country. The restrictions on arbitrage bind when money supplies grow at gross rates greater than the discount factor, in which case the nominal exchange rate is determinate and reflects the fundamentals of the two countries such as the initial stocks and growth rates of the two monies.

In addition to determining the nominal exchange rate, we have obtained three other main results. First, there are direct currency trades between the two countries, unless both money stocks are constant. A country is a net supplier of its currency in currency trades when both monies have positive net growth rates and a net recipient of its currency when both monies have negative net growth rates. Second, direct currency trades generate a lower relative price of money 1 to money 2 than does a chain of trades in the goods market if and only if money 1's stock grows more quickly than money 2's. Both results arise because direct currency trades transfer money balances across countries more quickly and less costly at the margin than a chain of trades through the goods market. Third, there are violations of the law of one price and the purchasing power 
parity, provided that the two monies have different growth rates. The cause for such violations is not the existence of non-traded goods or price rigidity but the costly exchange process and agents' inability to make arbitrage between matches instantaneously. The magnitudes of such violations are intimately related to the differential between the two monies' growth rates.

The search friction in the goods market is indispensable for our results, but the search friction in the currency market is not. Since all currency trades in our model take place at the same nominal exchange rate, our qualitative results will hold in an alternative setup where direct currency trades take place in a centralized market. As long as the currency market and the goods market are separated to prevent households from making arbitrage between the two markets, the nominal exchange rate will still be determinate. An example is as follows. The goods market opens before the currency market. A household dispatches all money holders to the goods market first, where the trading restrictions in our model apply. After the goods market closes, the household makes instantaneous trades between the two monies in the currency market at a Walrasian exchange rate, say $e_{w}$. The set of equilibria is the same as in our setup. In particular, if each household exchanges less than the household's money holding in the currency market, then $\Omega_{11} / \Omega_{12}=\Omega_{21} / \Omega_{22}=e_{w}$ and the equilibrium is very similar to the type $O$ equilibrium.

We plan to explore the properties of the model further in the following directions. First, we intend to examine numerically type $I$ and type $I I$ equilibria, which are left out here because we are unable to examine their properties analytically. Our conjecture is that the type $I$ equilibrium exists for large positive net money growth rates and the type $I I$ equilibrium exists for large negative net money growth rates. This is because the agents from at least one country want to exchange more than their money holdings in these cases and such a large volume of currency trades is necessary only when there are large (positive or negative) monetary transfers that constantly disturb the households' money holdings from their optimal levels.

Second, we intend to examine numerically the dynamic response of the equilibrium to money growth shocks and, in particular, to check whether real and nominal exchange rates can be 
positively correlated along the transitional path when responding to money growth shocks. This analysis is important because the positive correlation has been a puzzle in international finance (e.g., Mussa, 1986). Previous attempts to explain the puzzle have heavily relied on the assumption of nominal price rigidity. Our model has perfectly flexible prices and yet the two exchange rates respond to money growth shocks in the same way in the steady state if money growth rates pass a critical level (see the discussion on Proposition 7.2). It remains to check whether the two exchange rates can also be positively correlated along the transitional path. This requires us to go beyond the steady-state analysis and the deterministic environment. 


\section{References}

[1] Betts, C., Devereux, M.B., 2000. Exchange rate dynamics in a model of pricing-to-market, Journal of International Economics 50, 215-244.

[2] Craig, B., Waller, C.J., 2000. Currency portfolios and nominal exchange rates in a dual currency search economy (manuscript, University of Kentucky).

[3] Green, E., Zhou, R., 1998. A rudimentary random-matching model with divisible money and prices, Journal of Economic Theory 81, 252-271.

[4] Head, A., Shi, S., 1996. Search, inflation, and exchange rates (manuscript, Queen's University).

[5] Kareken, J., Wallace, N., 1981. On the indeterminacy of equilibrium exchange rates, Quarterly Journal of Economics 96, 207-222.

[6] Kiyotaki, N., Wright, R., 1989. On money as a medium of exchange, Journal of Political Economy 97, 927-954.

[7] Kiyotaki, N., Wright, R., 1993. A search-theoretic approach to monetary economics, American Economic Review 83, 63-77.

[8] Li, Y., Wright, R., 1998. Government transaction policy, media of exchange, and prices, Journal of Economic Theory 81, 290-313.

[9] Lucas, R.E. Jr., 1982. Interest rates and currency prices in a two-country world, Journal of Monetary Economics 10, 335-359.

[10] Manuelli, R., Peck, J., 1990. Exchange rate volatility in an equilibrium asset pricing model, International Economic Review 31, 559-574.

[11] Matsuyama, M., Kiyotaki, N., Matsui, A., 1993. Towards a theory of international currency, Review of Economic Studies 60, 283-307.

[12] Mussa, M., 1986. Nominal exchange rate regimes and the behavior of real exchange rates: evidence and implications, Carnegie-Rochester Conference Series on Public Policy 25, 117213.

[13] Obstfeld, M., 1998. Open-economy macroeconomics: developments in theory and policy, Scandinavian Journal of Economics 100, 247-275.

[14] Obstfeld, M., Rogoff, K., 1995. Exchange rate dynamics redux, Journal of Political Economy 103, 624-660.

[15] Shi, S., 1995. Money and prices: a model of search and bargaining, Journal of Economic Theory 67, 467-496.

[16] Shi, S., 1997. A divisible search model of fiat money, Econometrica 65, 75-102. 
[17] Shi, S., 1998. Search for a monetary propagation mechanism, Journal of Economic Theory 81, 314-352.

[18] Shi, S., 1999. Search, inflation, and capital accumulation, Journal of Monetary Economics $44,81-103$.

[19] Trejos, A., Wright, R., 1995. Search, bargaining, money, and prices, Journal of Political Economy 103, 118-141.

[20] Trejos, A., Wright, R., 1996. Search theoretic models of international currency, St. Louis Federal Reserve Bank Review 78, no. 3.

[21] Wang, W., 2000. Essays on Search Monetary Economy, Chapter IV (Ph.D. dissertation, Queen's University).

[22] Zhou, R., 1997. Currency exchange in a random search model, Review of Economic Studies 64, 289-310. 


\section{Appendices}

\section{A. Proof of Lemma 4.1}

To prove Lemma 4.1, we prove the following lemma first:

Lemma A.1. Consider the decision of an individual household from country 1. If $\omega_{12} / \omega_{11}>$ $\Omega_{22} / \Omega_{21}$, a type $I$ currency trade occurs but a type II currency trade does not. The terms of trade in a type $I$ currency trade and the conditions required for trade are

$$
\left(\begin{array}{c}
f_{11} \\
f_{22}
\end{array}\right)=\left\{\begin{array}{c}
\left(\begin{array}{c}
m_{11} / n_{11} \\
\left(\Omega_{21} \frac{m_{11}}{n_{11}}-\frac{\Delta_{1}}{2}\right) / \Omega_{22}
\end{array}\right), \quad \text { if }\left\{\begin{array}{c}
\frac{\Delta_{1}}{2}>\Omega_{21} \frac{m_{11}}{n_{11}}-\Omega_{22} \frac{M_{22}}{N_{22}} \\
\frac{\Delta_{1}}{2} \leq\left(\Omega_{21}-\frac{\omega_{11}}{\omega_{12}} \Omega_{22}\right) \frac{m_{11}}{n_{11}}
\end{array}\right. \\
\left(\begin{array}{c}
\left(\Omega_{22} \frac{M_{22}}{N_{22}}+\frac{\Delta_{1}}{2}\right) / \Omega_{21} \\
M_{22} / N_{22}
\end{array}\right), \quad \text { if }\left\{\begin{array}{c}
\frac{\Delta_{1}}{2} \leq \Omega_{21} \frac{m_{11}}{n_{11}}-\Omega_{22} \frac{M_{22}}{N_{22}} \\
\frac{\Delta_{1}}{2} \leq\left(\frac{\omega_{12}}{\omega_{11}} \Omega_{21}-\Omega_{22}\right) \frac{M_{22}}{N_{22}} .
\end{array}\right.
\end{array}\right.
$$

If $\omega_{12} / \omega_{11}<\Omega_{22} / \Omega_{21}$, a type II currency trade occurs but a type I currency trade does not. The terms of trade in a type II currency trade and the conditions required for trade are

$$
\left(\begin{array}{c}
f_{12} \\
f_{21}
\end{array}\right)=\left\{\begin{array}{c}
\left(\begin{array}{c}
m_{12} / n_{12} \\
\left(\Omega_{22} \frac{m_{12}}{n_{12}}-\frac{\Delta_{2}}{2}\right) / \Omega_{21}
\end{array}\right), \quad \text { if }\left\{\begin{array}{c}
\frac{\Delta_{2}}{2}>\Omega_{22} \frac{m_{12}}{n_{12}}-\Omega_{21} \frac{M_{21}}{N_{21}} \\
\frac{\Delta_{2}}{2} \leq\left(\Omega_{22}-\frac{\omega_{12}}{\omega_{11}} \Omega_{21}\right) \frac{m_{12}}{n_{12}}
\end{array}\right. \\
\left(\begin{array}{c}
\left(\Omega_{21} \frac{M_{21}}{N_{21}}+\frac{\Delta_{2}}{2}\right) / \Omega_{22} \\
M_{21} / N_{21}
\end{array}\right), \quad \text { if }\left\{\begin{array}{c}
\frac{\Delta_{2}}{2} \leq \Omega_{22} \frac{m_{12}}{n_{12}}-\Omega_{21} \frac{M_{21}}{N_{21}} \\
\frac{\Delta_{2}}{2} \leq\left(\frac{\omega_{11}}{\omega_{12}} \Omega_{22}-\Omega_{21}\right) \frac{M_{21}}{N_{21}} .
\end{array}\right.
\end{array}\right.
$$

If $\omega_{12} / \omega_{11}=\Omega_{22} / \Omega_{21}$, type $I$ currency trades occur if and only if $\Delta_{1}=0$ and type II currency trades occur if and only if $\Delta_{2}=0$; in either case the two agents both obtain zero surplus and trade any feasible quantities at an exchange rate $f_{22} / f_{11}=\Omega_{21} / \Omega_{22}$ (or $f_{12} / f_{21}=\Omega_{21} / \Omega_{22}$ ).

Proof. We prove the above lemma for the match between a country 1 holder of money 1 and a country 2 holder of money 2 . The proof is similar for the match between a country 1 holder of money 2 and a country 2 holder of money 1 .

The match will not result in trade if $\Delta_{1}<0$. So, suppose $\Delta_{1} \geq 0$. Then, (3.7) becomes $f_{11} \geq\left(\frac{\Delta_{1}}{2}+\Omega_{22} f_{22}\right) / \Omega_{21}$. We call the equality form of this constraint the respondent's minimum surplus line. This constraint and (3.7) - (3.8) form the feasibility set of the trade, depicted by the shaded area in Figure 1 for the case where the intersection between the respondent's minimum 
surplus line and the bound $f_{11}=m_{11} / n_{11}$ has $f_{22}<M_{22} / N_{22}$ (like point $A 1$ ). The surplus of trade to the proposing household (country 1 household) is $\left(\omega_{12} f_{22}-\omega_{11} f_{11}\right)$, and so the line $f_{11}=\left(\omega_{12} f_{22}-c\right) / \omega_{11}$ depicts the combinations of $\left(f_{11}, f_{22}\right)$ that give the proposer a surplus $c$. We call these lines the proposer's iso-surplus lines. For the country 1 household to trade, it must obtain a non-negative surplus. So, we consider only $c \geq 0$. Note that the proposer's surplus increases when the proposer's iso-surplus line moves southeast.

Figure 1 here.

If $\omega_{12} / \omega_{11}<\Omega_{22} / \Omega_{21}$, the proposer's iso-surplus line is flatter than the respondent's minimum surplus line. The solution is $\left(f_{11}, f_{22}\right)=(0,0)$, i.e., there is no trade. If $\omega_{12} / \omega_{11}=\Omega_{22} / \Omega_{21}$, the proposer's iso-surplus line and the respondent's minimum surplus line are parallel to each other. In this instance the only case for trade is when the respondent's minimum surplus line goes through the origin, i.e., when $\Delta_{1}=0$. If $\Delta_{1}=0$, the solution is anywhere between the origin and point $A 1$. Both agents obtain zero surplus in this case.

If $\omega_{12} / \omega_{11}>\Omega_{22} / \Omega_{21}$, the proposer's iso-surplus line is steeper than the respondent's minimum surplus line. The solution is point $A 1$. That is,

$$
f_{11}=\frac{m_{11}}{n_{11}}, f_{22}=\left(\Omega_{21} \frac{m_{11}}{n_{11}}-\frac{\Delta_{1}}{2}\right) / \Omega_{22} .
$$

As stated before, this solution is valid only when the intersection between the respondent's minimum surplus line and the bound $f_{11}=m_{11} / n_{11}$ has $f_{22}<M_{22} / N_{22}$, i.e., only when

$$
\frac{\Delta_{1}}{2}>\Omega_{21} \frac{m_{11}}{n_{11}}-\Omega_{22} \frac{M_{22}}{N_{22}} .
$$

For this trade to happen, the proposer must also obtain non-negative surplus, i.e.,

$$
\frac{\Delta_{1}}{2} \leq\left(\Omega_{21}-\Omega_{22} \frac{\omega_{11}}{\omega_{12}}\right) \frac{m_{11}}{n_{11}}
$$

These are the conditions given by the first case in (A.1).

Still consider the case $\omega_{12} / \omega_{11}>\Omega_{22} / \Omega_{21}$, but now suppose that the intersection between the respondent's minimum surplus line and the bound $f_{11}=m_{11} / n_{11}$ has $f_{22}>M_{22} / N_{22}$. In this 
case the solution is at point $A 3$ and satisfies $f_{11}<m_{11} / n_{11}$. A procedure similar to the above shows that the second case in (A.1) applies and the requirement for trade, $\Delta_{1} / 2 \leq \Omega_{21} m_{11} / n_{11}-$ $\Omega_{22} M_{22} / N_{22}$, should hold with strict inequality.

Now suppose that the respondent's minimum surplus line passes through point $A 2$. Then the solution is at point $A 2$. Although the solution satisfies $f_{11}=m_{11} / n_{11}$, the constraint $f_{11} \leq$ $m_{11} / n_{11}$ is not binding to the proposer. To see this, suppose that the constraint $f_{11} \leq m_{11} / n_{11}$ binds in this case. Then the proposer would like to offer more money to the trading partner if he/she had more money. Since the solution has exactly $f_{11}=m_{11} / n_{11}$, the proposer's household can make the constraint slack by reducing $n_{11}$ slightly. This alternative choice of $n_{11}$ increases utility, contradicting the optimality of the original choice. Therefore, $\partial f_{11} / \partial\left(m_{11} / n_{11}\right)=0$ even when $f_{11}=m_{11} / n_{11}$. (A formal proof is as follows. Let $\mu_{I}=\partial f_{11} / \partial\left(m_{11} / n_{11}\right)$. Suppose $f_{11}=m_{11} / n_{11}$ and the constraint $f_{11} \leq m_{11} / n_{11}$ binds. Then $\mu_{I}>0$. Also, since $n_{11}$ is chosen optimally, the marginal utility from changing $n_{11}$ (given by the right-hand side of (4.12)) must be zero. Now consider an alternative choice $\hat{n}_{11}=n_{11}-\varepsilon$ where $\varepsilon$ is an arbitrarily small and positive number. For sufficiently small $\varepsilon$, the solution to the currency trade has $f_{11}<m_{11} / \hat{n}_{11}$ and so $\hat{\mu}_{I}=0$. The right-hand side of (4.12) becomes strictly positive, which contradicts the optimality of the choice $n_{11}$.) This completes the proof of Lemma A.1.

Now we prove Lemma 4.1. Impose symmetry, as an equilibrium requires, so that $\omega_{i k}=$ $\Omega_{i k}, f_{i k}=F_{i k}, m_{i k}=M_{i k}$, and $n_{i k}=N_{i k}$. We can compute $\Delta_{1}$ and $\Delta_{2}$ by substituting the corresponding terms of trade from (A.1) and (A.2) into (3.5) and (3.12). Substituting the results for $\Delta_{1}$ and $\Delta_{2}$ into (A.1) and (A.2), we obtain (4.4) and (4.5). When $\Pi=0$, one can verify $\Delta_{1}=\Delta_{2}=0$ and so a type $O$ equilibrium exists. One can also verify that the two agents in a currency trade each get a half of the match surplus in all three types of equilibria.

QED 


\section{B. Derivations for subsection 4.3}

In this appendix we derive the conditions (4.8), (4.9) and (4.12) in subsection 4.3. The derivations for (4.10), (4.11) and (4.13) are similar.

From a country 1 household's maximization problem, the first-order conditions for $m_{1 k}^{\prime}$ are as follows:

$$
\begin{aligned}
\omega_{11} / \beta= & \omega_{11}^{\prime}+\left(\lambda_{11}^{\prime} \frac{W_{11}^{\prime}}{N_{11}^{\prime}}+\lambda_{11}^{f^{\prime}} \frac{W_{11}^{f^{\prime}}}{N_{11}^{\prime}}\right) \\
& +G_{I}^{\prime} \frac{Y_{12}^{\prime}}{N_{11}^{\prime}}\left[\omega_{12}^{\prime} \frac{\partial f_{22}^{\prime}}{\partial\left(m_{11}^{\prime} / n_{11}^{\prime}\right)}-\omega_{11}^{\prime} \frac{\partial f_{11}^{\prime}}{\partial\left(m_{11}^{\prime} / n_{11}^{\prime}\right)}\right], \\
\omega_{12} / \beta= & \omega_{12}^{\prime}+\left(\lambda_{12}^{\prime} \frac{W_{12}^{\prime}}{N_{12}^{\prime}}+\lambda_{12}^{f^{\prime}} \frac{W_{12}^{f^{\prime}}}{N_{12}^{\prime}}\right) \\
& +G_{I I}^{\prime} \frac{Y_{21}^{\prime}}{N_{12}^{\prime}}\left[\omega_{11}^{\prime} \frac{\partial f_{21}^{\prime}}{\partial\left(m_{12}^{\prime} / n_{12}^{\prime}\right)}-\omega_{12}^{\prime} \frac{\partial f_{12}^{\prime}}{\partial\left(m_{12}^{\prime} / n_{12}^{\prime}\right)}\right],
\end{aligned}
$$

From (A.1) and (A.2), an individual household's money holdings have the following influence on the terms of trade in the currency-trading matches:

$$
\frac{\partial\left(f_{11}, f_{22}\right)}{\partial\left(m_{11} / n_{11}\right)}=\left(1, \frac{\Omega_{21}}{\Omega_{22}}\right) \mu_{I}, \quad \frac{\partial\left(f_{12}, f_{21}\right)}{\partial\left(m_{12} / n_{12}\right)}=\left(1, \frac{\Omega_{22}}{\Omega_{21}}\right) \mu_{I I}
$$

where $\mu_{I}$ and $\mu_{I I}$ are defined in (4.3) in equilibrium. Substituting these derivatives into (B.1) and (B.2), we obtain (4.8) and (4.9) in equilibrium.

To obtain (4.12), we derive the first-order condition for $n_{11}$ :

$$
\begin{aligned}
0= & B\left(\frac{W_{11}}{N_{11}} q_{11}+\frac{W_{11}^{f}}{N_{11}} q_{21}^{f}-\frac{W_{12}}{N_{12}} q_{12}-\frac{W_{12}^{f}}{N_{12}} q_{22}^{f}\right) \\
& -\frac{W_{11}}{N_{11}}\left(\omega_{11}+\lambda_{11}\right) x_{11}-\frac{W_{11}^{f}}{N_{11}}\left(\omega_{11}+\lambda_{11}^{f}\right) x_{11}^{f} \\
& +\frac{W_{12}}{N_{12}}\left(\omega_{12}+\lambda_{12}\right) x_{12}+\frac{W_{12}^{f}}{N_{12}}\left(\omega_{12}+\lambda_{12}^{f}\right) x_{12}^{f} \\
& +\frac{Y_{12}}{N_{11}} G_{I}\left(\omega_{12} f_{22}-\omega_{11} f_{11}\right)+\frac{Y_{21}}{N_{12}} G_{I I}\left(\omega_{12} f_{12}-\omega_{11} f_{21}\right) \\
& +G_{I} \frac{Y_{12}}{N_{11}} \frac{m_{11}}{n_{11}}\left[\omega_{11} \frac{\partial f_{11}}{\partial\left(m_{11} / n_{11}\right)}-\omega_{12} \frac{\partial f_{22}}{\partial\left(m_{11} / n_{11}\right)}\right] \\
& +G_{I I} \frac{Y_{21}}{N_{12}} \frac{m_{12}}{n_{12}}\left[\omega_{11} \frac{\partial f_{21}}{\partial\left(m_{12} / n_{12}\right)}-\omega_{12} \frac{\partial f_{12}}{\partial\left(m_{12} / n_{12}\right)}\right] .
\end{aligned}
$$

To simplify, use (3.1), (3.3), (4.6), and (4.7) to obtain:

$$
\left(\Omega_{i k}+\Lambda_{i k}\right) X_{i k}=\frac{B}{\sigma} Q_{i k}, \quad\left(\Omega_{i k}+\Lambda_{i k}^{f}\right) X_{i k}^{f}=\frac{B}{\sigma} Q_{i^{\prime} k}^{f}
$$

Substituting these relations and (B.3) into (B.4), we obtain (4.12). 


\section{Proofs of Lemma 5.1 and Proposition 5.2}

We prove Lemma 5.1 first. Substituting $X_{i k}=X_{i k}^{f}=M_{i k} / N_{i k}$ into (3.1) and (3.3), we have the following equations (for $i^{\prime} \neq i$ and $i, k=1,2$ ):

$$
\Omega_{i k}=\frac{N_{i k}}{M_{i k}} \phi\left(Q_{i k}\right)=\frac{N_{i^{\prime} k}}{M_{i^{\prime} k}} \phi\left(Q_{i k}^{f}\right)
$$

The equations in (5.2) immediately follow. Using (5.2) and (C.1) we can write $\Lambda$ and $\Lambda^{f}$ from (4.6) and (4.7) as follows $\left(i^{\prime} \neq i, i, k=1,2\right)$ :

$$
\left.\begin{array}{c}
\Lambda_{i k}=\frac{N_{i k}}{M_{i k}}\left(\frac{B}{\sigma} Q_{i k}-Q_{i k}^{\sigma}\right), \\
\Lambda_{i i}^{f}=\frac{N_{i i}}{M_{i i}}\left(\frac{B}{\sigma} Q_{i^{\prime} i} \theta_{i}^{1 / \sigma}-Q_{i i}^{\sigma}\right), \\
\Lambda_{i^{\prime} i}^{f}=\frac{N_{i^{\prime} i}}{M_{i^{\prime} i}}\left(\frac{B}{\sigma} Q_{i i} \theta_{i}^{-1 / \sigma}-Q_{i^{\prime} i}^{\sigma}\right) .
\end{array}\right\}
$$

Substituting $\left(\Omega, \Lambda, \Lambda^{f}\right)$ from (C.1)-(C.3) into (4.8)-(4.11), noticing $\Pi=0$, and imposing stationarity (which implies $M_{i k}^{\prime} / M_{i k} \rightarrow \gamma_{k}$ ), we obtain (5.3) and (5.4).

To get (5.5), we substitute $\Pi=0$ into (4.12) and (4.13), resulting in the following relations $\left(\right.$ for $\left.i^{\prime} \neq i, i=1,2\right)$ :

$$
Q_{i^{\prime} i}+\alpha \theta_{i}^{-1 / \sigma} Q_{i i}=\frac{W_{i^{\prime} i^{\prime}} / N_{i^{\prime} i^{\prime}}}{W_{i^{\prime} i} / N_{i^{\prime} i}}\left(Q_{i^{\prime} i^{\prime}}+\alpha \theta_{i^{\prime}}^{1 / \sigma} Q_{i i^{\prime}}\right)
$$

Substituting this into (5.3) and (5.4) we obtain (5.5). This completes the proof of Lemma 5.1.

We now prove Proposition 5.2. Use the definition of $\theta_{i}$ in (5.1) to derive:

$$
\frac{M_{i i}}{M_{i}}=\frac{N_{i i} \theta_{i}}{N_{i^{\prime} i}+N_{i i} \theta_{i}}
$$

Substitute the $\Omega$ 's from (C.1) and (5.5) into the conditions $\Omega_{11} / \Omega_{12}=e=\Omega_{21} / \Omega_{22}$ (implied by $\Pi=0)$. We have

$$
\frac{e M_{1}}{M_{2}}=\frac{1}{\theta_{1} A\left(N_{11}\right)} \cdot \frac{\theta_{1} N_{11}+N_{21}}{\theta_{2} N_{22}+N_{12}}=\theta_{2} A\left(N_{22}\right) \cdot \frac{\theta_{1} N_{11}+N_{21}}{\theta_{2} N_{22}+N_{12}} .
$$

The second equality requires

$$
A\left(N_{22}\right)=1 /\left[\theta_{1} \theta_{2} A\left(N_{22}\right)\right]
$$


Substituting (5.5) and (C.7) into (C.4), we have (5.7).

Lemma C.1 below shows that the solution to (5.7) exists and is unique. It also establishes the properties of the solution $N\left(\gamma_{1}, \gamma_{2}\right)$ listed in (i) of the proposition. Notice that (5.7) has the following symmetry: If $N_{11}=N^{*}$ solves the equation for $i=1$, then $N_{22}=1-s-N^{*}$ solves the equation for $i=2$. Therefore, $N_{21}=N_{11}$ and $N_{22}=N_{12}$. This further implies $A\left(N_{22}\right)=1 / A\left(N_{11}\right)$ from (5.7), $\theta_{2}=1 / \theta_{1}$ from (C.7), and (5.8) from (C.6). Clearly, (5.8) uniquely determines $e$ for any given $\left(\gamma_{1}, \gamma_{2}\right)$ and initial money stocks $\left(M_{10}, M_{20}\right)$.

To see that the nominal exchange rate is a decreasing function of $\gamma_{1}$ and an increasing function of $\gamma_{2}$, note that (5.7) requires $A(N)$ to be a decreasing function of $N$. So, the right-hand side of (5.8) is an increasing function of $N\left(\gamma_{1}, \gamma_{2}\right)$. Given the properties of $N\left(\gamma_{1}, \gamma_{2}\right)$ listed in (i) of the Proposition, the right-hand side of (5.8) is a decreasing function of $\gamma_{1}$ and an increasing function of $\gamma_{2}$. Since $M_{2} / M_{1}$ is also a decreasing function of $\gamma_{1}$ and an increasing function of $\gamma_{2},(5.8)$ requires the nominal exchange rate to depend on $\left(\gamma_{1}, \gamma_{2}\right)$ in these ways as well.

To see why $\left(D, \theta_{1}\right)$ satisfy $(5.9)$ and $(5.10)$, notice that the net receipt of money 2 by country 1 households in the two-way currency trades is $Y_{12} f_{22}-Y_{21} f_{12}=e D$. In the steady state, the quantities $M_{11} / M_{1}, M_{12} / M_{2}$ and $D / M_{1}$ are all stationary. The laws of motion of monies, (3.14) and (3.15), then imply

$$
\begin{gathered}
\frac{M_{11}}{M_{1}}=\frac{\gamma_{1}-1+\alpha W_{11} / N_{11}-D / M_{1}}{\gamma_{1}-1+2 \alpha W_{11} / N_{11}}, \\
\frac{M_{12}}{M_{2}}=\frac{\alpha W_{12} / N_{12}+\left(e M_{1} / M_{2}\right)\left(D / M_{1}\right)}{\gamma_{2}-1+2 \alpha W_{12} / N_{12}},
\end{gathered}
$$

where we have used the properties of $N_{i k}$ in (i) of the Proposition. With the same properties, (C.5) implies $M_{11} / M_{1}=M_{12} / M_{2}=\theta_{1} /\left(1+\theta_{1}\right)$. Substituting these into the above two equations, we can solve $\left(D / M_{1}, \theta_{1}\right)$ and verify (5.9) and (5.10). This completes the proof of Proposition 5.2.

Lemma C.1. There is a unique $N_{i i} \in(0,1-s)$ that solves (5.7), provided $\gamma_{1}, \gamma_{2} \geq \beta$. Moreover, $N_{11}$ is a decreasing function of $\gamma_{1}$ and an increasing function of $\gamma_{2}$, with $N_{11}=(1-s) / 2$ when $\gamma_{1}=\gamma_{2}$ 
Proof. Let

$$
w(N) \equiv \frac{(s / N)^{1-\psi}}{(1+\alpha) J} .
$$

Then $w(\cdot)$ is a decreasing and convex function, with $w(0)=\infty$. Also, $W_{11} / N_{11}=w\left(N_{11}\right)$ and $W_{12} / N_{12}=w\left(1-s-N_{11}\right)$. Let us suppress the subscripts of $N_{11}$ and rewrite (5.7) for $i=1$ as $\operatorname{LHS}(N)=1$ where

$$
\operatorname{LHS}(N) \equiv \frac{\left(\gamma_{1} / \beta-1\right)[w(N)]^{-\sigma}+(1+\alpha)[w(N)]^{-(\sigma-1)}}{\left(\gamma_{2} / \beta-1\right)[w(1-s-N)]^{-\sigma}+(1+\alpha)[w(1-s-N)]^{-(\sigma-1)}} .
$$

Since $w(\cdot)$ is a decreasing function and $\sigma>1$, the numerator of $L H S(N)$ is an increasing function

of $N$ and the denominator is a decreasing function of $N$, provided $\gamma_{1}, \gamma_{2} \geq \beta$. Thus, $L H S^{\prime}(N)>0$. If there is any solution to $\operatorname{LHS}(N)=1$ then the solution is unique. Since

$$
L H S(N) \rightarrow 0 \text { when } N \rightarrow 0, \text { and } \rightarrow+\infty \text { when } N \rightarrow 1-s,
$$

there is indeed a unique $N \in(0,1-s)$ that solves $\operatorname{LHS}(N)=1$.

For any fixed $N, \operatorname{LHS}(N)$ is an increasing function of $\gamma_{1}$ and a decreasing function of $\gamma_{2}$. Thus, the solution to $\operatorname{LHS}(N)=1$ is a decreasing function of $\gamma_{1}$ and an increasing function of $\gamma_{2}$. When $\gamma_{1}=\gamma_{2}, \operatorname{LHS}(N)=1$ if and only if $w(N)=w(1-s-N)$ and so the solution for $N$ in this case is $N=(1-s) / 2$.

QED

\section{Proof of Lemma 5.3}

For Lemma 5.3, the properties of $D$ are apparent from (5.9). Now we show that $\Omega_{1 k} / \Omega_{2 k}<1$ iff $\theta_{1}>1$. That is, $Q_{21}>Q_{11} \theta_{1}^{-1 / \sigma}$ iff $\theta_{1}>1$. Recall that $\left(Q_{11}, Q_{21}\right)$ solve (5.3) and (5.4). Noting $N_{21}=N_{11}$ in the type $O$ equilibrium, we can rewrite these equations for $i=1$ as

$$
\begin{aligned}
& Q_{21}=L 1\left(Q_{11}\right) \equiv \frac{\theta_{1}^{-1 / \sigma}}{\alpha}\left[\frac{\sigma}{B}\left(1+\alpha+\left(\frac{\gamma_{1}}{\beta}-1\right) \frac{N_{11}}{W_{11}}\right) Q_{11}^{\sigma}-Q_{11}\right] \\
& Q_{11}=L 2\left(Q_{21}\right) \equiv \frac{\theta_{1}^{1 / \sigma}}{\alpha}\left[\frac{\sigma}{B}\left(1+\alpha+\left(\frac{\gamma_{1}}{\beta}-1\right) \frac{N_{11}}{W_{11}}\right) Q_{21}^{\sigma}-Q_{21}\right]
\end{aligned}
$$

In Figure 2 we graph these curves for given $\theta_{1}$ whose intersection is the solutions for $\left(Q_{11}, Q_{21}\right)$. We also draw the line $Q_{21}=Q_{11} \theta_{1}^{-1 / \sigma}$. It is clear from the diagram that the solutions for 
$\left(Q_{11}, Q_{21}\right)$ satisfy $Q_{21}>Q_{11} \theta_{1}^{-1 / \sigma}$ if and only if the line $Q_{21}=Q_{11} \theta_{1}^{-1 / \sigma}$ intersects the curve $Q_{21}=L 1\left(Q_{11}\right)$ before intersecting the curve $Q_{11}=L 2\left(Q_{21}\right)$. By solving for the intersections, we can verify that $Q_{21}>Q_{11} \theta_{1}^{-1 / \sigma}$ if and only if $\theta_{1}>1$.

Figure 2 here.

To show the properties of $\theta_{1}$, we use (5.9) and (5.10) to conclude that $\theta_{1}>1$ if and only if

$$
\left(\gamma_{1}-1\right) \frac{e M_{1}}{M_{2}}>\gamma_{2}-1
$$

If $\gamma_{1}=\gamma_{2}$, then $N_{i k}=(1-s) / 2$ for all $i, k=1,2$ and so $e M_{1} / M_{2}=1$ from (5.8), in which case (D.1) holds with equality, and so $\theta_{1}=1$.

Now, we consider the case $\gamma_{1}, \gamma_{2}<1$ and show property (ii) in the lemma. When $\gamma_{1}, \gamma_{2}<1$, (D.1) becomes $e M_{1} / M_{2}<\left(\gamma_{2}-1\right) /\left(\gamma_{1}-1\right)$. Substituting (5.8) for $e M_{1} / M_{2}$ and (5.7) for $A\left(N_{11}\right)$, we can rewrite this condition as $N\left(\gamma_{1}, \gamma_{2}\right)<N_{a}\left(\gamma_{1}, \gamma_{2}\right)$ where $N\left(\gamma_{1}, \gamma_{2}\right)$ is the equilibrium value of $N_{11}$ and $N_{a}\left(\gamma_{1}, \gamma_{2}\right)$ is defined as follows:

$$
N_{a}\left(\gamma_{1}, \gamma_{2}\right) \equiv \frac{1-s}{1+\left(\frac{\gamma_{1}-1}{\gamma_{2}-1}\right)^{\frac{1}{1+\sigma(1-\psi)}}} .
$$

Recall that $N\left(\gamma_{1}, \gamma_{2}\right)$ satisfies $L H S(N)=1$, where $L H S(N)$ is defined in (C.8) and is an increasing function. Then, $N\left(\gamma_{1}, \gamma_{2}\right)<N_{a}\left(\gamma_{1}, \gamma_{2}\right)$ iff $\operatorname{LHS}\left(N_{a}\left(\gamma_{1}, \gamma_{2}\right)\right)>1$. Notice that $N_{a}\left(\gamma_{1}, \gamma_{2}\right)$ is an increasing function of $\gamma_{1}$ when $\gamma_{1}, \gamma_{2}<1$. In this case we can show that $\operatorname{LHS}\left(N_{a}\left(\gamma_{1}, \gamma_{2}\right)\right)$ is an increasing function of $\gamma_{1}$. Since $\operatorname{LHS}\left(N_{a}(\gamma, \gamma)\right)=1$, then $\operatorname{LHS}\left(N_{a}\left(\gamma_{1}, \gamma_{2}\right)\right)>1$ iff $\gamma_{1}>\gamma_{2}$. That is, $\theta_{1}>1$ iff $\gamma_{1}>\gamma_{2}$.

Now consider the case $\gamma_{1}, \gamma_{2}>1$ and show property (iii) in the lemma. When $\gamma_{1}, \gamma_{2}>1$, (D.1) becomes $e M_{1} / M_{2}>\left(\gamma_{2}-1\right) /\left(\gamma_{1}-1\right)$, which is equivalent to $\operatorname{LH} S\left(N_{a}\left(\gamma_{1}, \gamma_{2}\right)\right)<1$. Now $N_{a}\left(\gamma_{1}, \gamma_{2}\right)$ is a decreasing function of $\gamma_{1}$ and $\operatorname{LHS}\left(N_{a}\left(\gamma_{1}, \gamma_{2}\right)\right)$ can be either increasing or decreasing in $\gamma_{1}$ in general (LHS depends on $\gamma_{1}$ both through $N\left(\gamma_{1}, \gamma_{2}\right)$ and separately). Nevertheless, we can verify the following:

$$
\left[\frac{d}{d \gamma_{1}} \operatorname{LHS}\left(N_{a}\left(\gamma_{1}, \gamma_{2}\right)\right)\right]_{\substack{\gamma_{1}=\gamma_{2}=\gamma \\ 44}}>0 \Longleftrightarrow \gamma>\gamma_{a}
$$


where $\gamma_{a}$ is defined in the lemma. Suppose $\gamma_{1}$ is close to $\gamma_{2}$. When $\gamma_{2}>\gamma_{a}, \operatorname{LHS}\left(N_{a}\left(\gamma_{1}, \gamma_{2}\right)\right)$ is locally increasing in $\gamma_{1}$, and so $\operatorname{LHS}\left(N_{a}\left(\gamma_{1}, \gamma_{2}\right)\right)<1$ iff $\gamma_{1}<\gamma_{2}$. When $\gamma_{2}<\gamma_{a}, \operatorname{LHS}\left(N_{a}\left(\gamma_{1}, \gamma_{2}\right)\right)$ is locally decreasing in $\gamma_{1}$, and so $\operatorname{LHS}\left(N_{a}\left(\gamma_{1}, \gamma_{2}\right)\right)<1$ iff $\gamma_{1}>\gamma_{2}$. Putting the two cases together, we have $\theta_{1}>1$ iff $\left(\gamma_{1}-\gamma_{2}\right)\left(\gamma_{2}-\gamma_{a}\right)<0$.

QED

\section{E. Proof of Proposition 6.1}

By definition, $M_{1}^{\prime}=\gamma_{1} M_{1}$. Multiplying by $\Omega_{11}$ and noticing $\Omega_{11} M_{1}^{\prime}=\beta\left(\Omega_{11}^{\prime} M_{1}^{\prime}\right)$, we have $\beta\left(\Omega_{11}^{\prime} M_{1}^{\prime}\right)=\gamma_{1}\left(\Omega_{11} M_{1}\right)$. In the steady state this becomes $\left(\gamma_{1}-\beta\right)\left(\Omega_{11} M_{1}\right)=0$. Thus, $\gamma_{1}=\beta$,

provided $\Omega_{11} M_{1}>0$ in the steady state. To show $\Omega_{11} M_{1}>0$, notice that at least one pair among $\left(N_{i 1}, Q_{i 1}\right)$ and $\left(N_{i 1}, Q_{i^{\prime} 1}^{f}\right)$ is strictly positive (otherwise money 1 is not valued). Suppose, for example, $N_{11}>0$ and $Q_{11}>0$, then (3.1) implies

$$
\Omega_{11} M_{1} \geq \Omega_{11} M_{11} \geq N_{1} \Omega_{11} X_{11}=N_{11} \phi\left(Q_{11}\right)>0 .
$$

As argued above, this implies $\gamma_{1}=\beta$. Similarly, $\gamma_{2}=\beta$.

Imposing $\gamma_{1}=\beta$ in (3.14), we have:

$$
M_{11}^{\prime}=\beta M_{11}+(\beta-1) M_{21}-\xi_{1},
$$

where $\xi_{1} \equiv D+\alpha\left(W_{11} X_{11}^{f}-W_{21} X_{21}^{f}\right)$ and $D$ is the net payment of money 1 by country 1 in the two-way currency trades defined in Proposition 5.2. If country 1 households hold a strictly positive amount of money 1 and exchange for a strictly positive amount of goods using money 1, then $\Omega_{11} M_{11}$ must be strictly positive. Multiplying the above equation by $\Omega_{11}$ and imposing stationarity we have $\xi_{1}=(\beta-1) M_{21}$, which in turn implies $M_{11}^{\prime}=\beta M_{11}$ from the above equation. Since $M_{1}^{\prime}=\beta M_{1}$ also, $M_{21}^{\prime}=\beta M_{21}$. Similarly, when $\gamma_{2}=\beta$, we need $M_{i 2}^{\prime}=\beta M_{i 2}$ for $i=1,2$, which is equivalent to $\xi_{2}=(\beta-1) M_{12}$ where $\xi_{2}=e D+\alpha\left(W_{22} X_{22}^{f}-W_{12}^{f} X_{12}^{f}\right)$.

Now we fix the nominal exchange rate at an arbitrary level $e$ and construct an equilibrium. Recall that $\Omega_{11} / \Omega_{21}=\Omega_{12} / \Omega_{22}$. To simplify the task, we construct an equilibrium for the case where $\Omega_{11}=\Omega_{21}$. In this case, (4.6) and (4.7) imply

$$
Q_{i k}=Q_{i k}^{f}=(B / \sigma)^{1 /(\sigma-1)} \equiv Q .
$$


Then (4.12) and (4.13) are satisfied if and only if $W_{11} / N_{11}=W_{12} / N_{12}$ and $W_{22} / N_{22}=W_{21} / N_{21}$, i.e., if and only if $N_{i k}=(1-s) / 2$ for $i, k=1,2$. Denote this common value of the $N$ 's as $N$.

The other equilibrium requirements are (3.1), (3.3), $M_{i k}^{\prime} / M_{i k}=\beta$, and $\Lambda_{i k}=\Lambda_{i k}^{f}=0$. The conditions (3.1) and (3.3) require the following for $i=1,2$ :

$$
X_{i 1}^{f}=X_{i 1}=\frac{Q^{\sigma}}{\Omega_{11}}, \quad X_{i 2}^{f}=X_{i 2}=\frac{e Q^{\sigma}}{\Omega_{11}}
$$

These lead to $\xi_{1}=D$ and $\xi_{2}=e D$. Since the requirements $M_{i k}^{\prime} / M_{i k}=\beta(i, k=1,2)$ are equivalent to $\xi_{1}=(\beta-1) M_{21}$ and $\xi_{2}=(\beta-1) M_{12}$, they now become

$$
D=(\beta-1) M_{21}=(\beta-1) M_{12} / e .
$$

Finally, the conditions $\Lambda_{i k}, \Lambda_{i k}^{f}=0(i, k=1,2)$ require $M_{i k} \geq N X_{i k}$. That is,

$$
\min \left\{M_{11}, M_{21}\right\} \geq \frac{N Q^{\sigma}}{\Omega_{11}}, \quad \min \left\{M_{12}, M_{22}\right\} \geq \frac{e N Q^{\sigma}}{\Omega_{11}}
$$

With $M_{12}=e M_{21}$, we can rewrite these conditions as

$$
\Omega_{11} \geq N Q^{\sigma} / \min \left\{M_{11}, M_{1}-M_{11}, \frac{M_{2}}{e}-\left(M_{1}-M_{11}\right)\right\}
$$

Therefore, for an arbitrarily fixed $e\left(\leq M_{2} /\left(M_{1}-M_{11}\right)\right)$ an equilibrium exists and satisfies the following conditions: (i) the initial money holdings satisfy $M_{120} / M_{210}=e$ (but the level of $M_{120}$ or $M_{210}$ is indeterminate); (ii) the values of monies satisfy (E.2), $\Omega_{i k}=\Omega$ (for all $i, k=1,2$ ) and $\Omega=\beta \Omega^{\prime}$; (iii) the quantities of goods traded in all money-goods trading matches are $Q$ and the quantities of monies traded satisfy (E.1); (iv) the quantities of monies traded in currency trades are such that the net payment of money 1 by country 1 households is $D=(\beta-1) M_{21}$; and (v) all the $N$ 's are equal to $(1-s) / 2$.

QED 


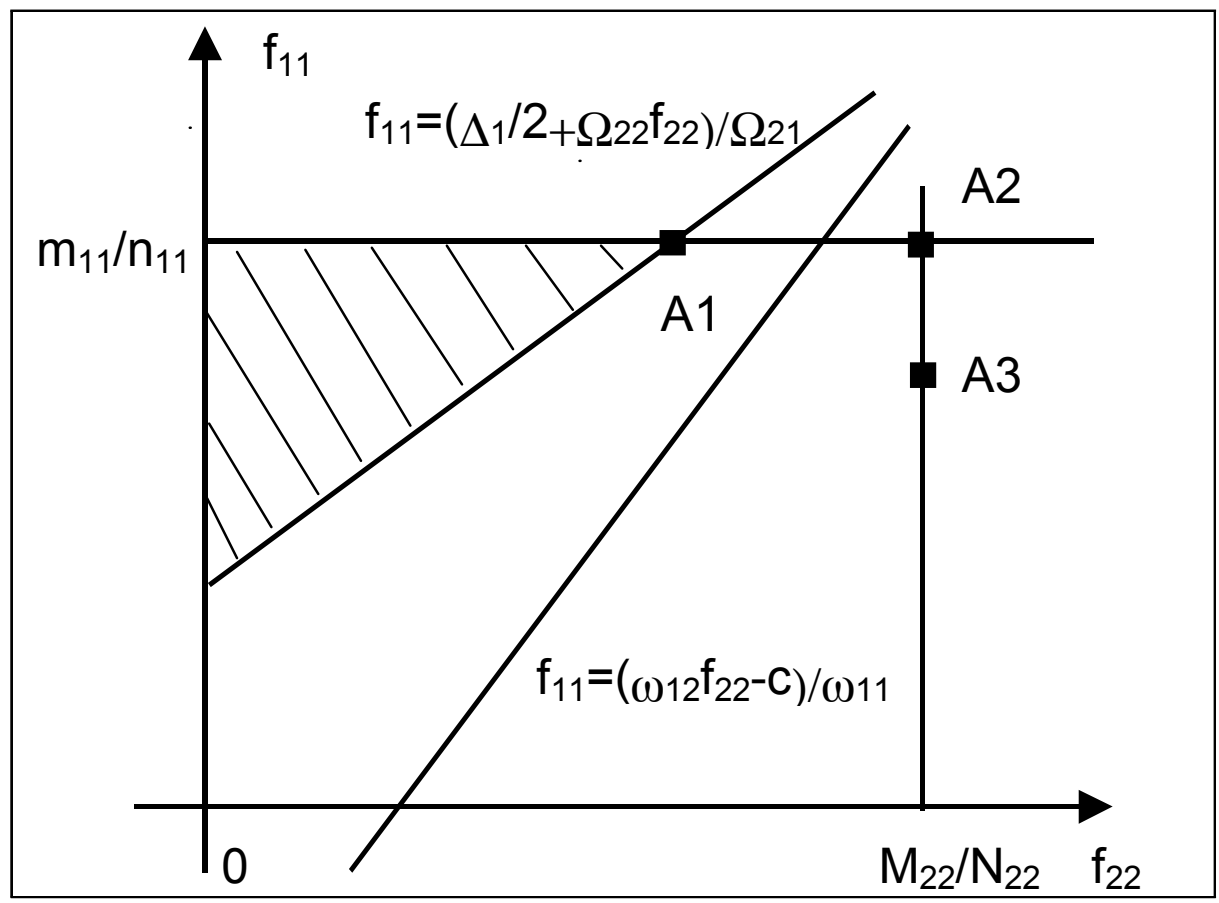

Figure 1. Solution to the currency trade

Title of paper: A fundamental theory of exchange rates and direct currency trades Authors' names: Allen Head, Shouyong Shi 


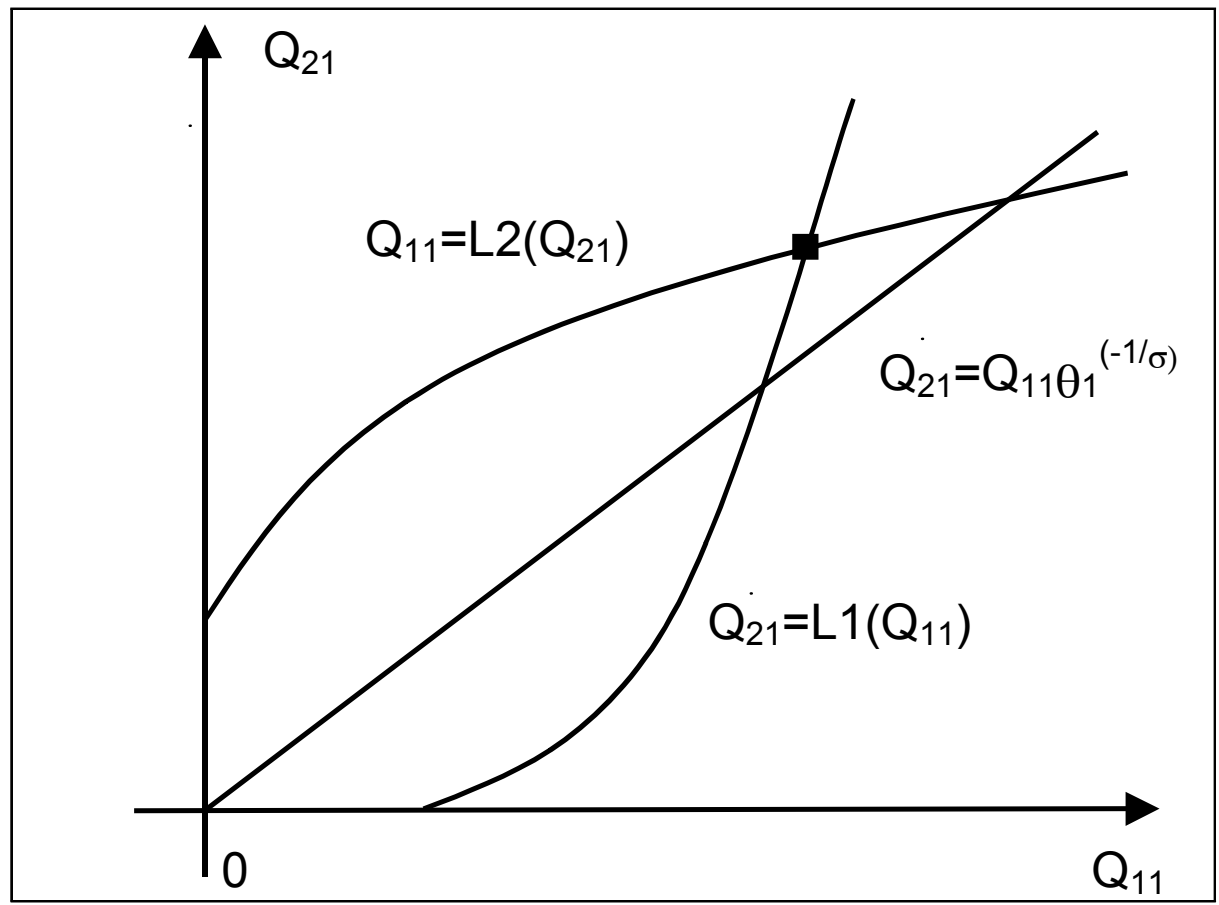

Figure 2. Solutions for $\left(Q_{11}, Q_{21}\right)$

Title of paper: A fundamental theory of exchange rates and direct currency trades Authors' names: Allen Head, Shouyong Shi 